\title{
Insights into glucosinolate accumulation and metabolic pathways in Isatis indigotica Fort.
}

\author{
Tianyi Zhang ${ }^{1}$, Rui Liu², Jinyu Zheng ${ }^{1}$, Zirong Wang ${ }^{1}$, Tian'e Gao' ${ }^{1}$ Miaomiao Qin ${ }^{1}$, Xiangyang Hu' , \\ Yuanyuan Wang ${ }^{1}$, Shu Yang ${ }^{3}$ and Tao Li ${ }^{i^{*}}$
}

\begin{abstract}
Background: Glucosinolates (GSLs) play important roles in defending against exogenous damage and regulating physiological activities in plants. However, GSL accumulation patterns and molecular regulation mechanisms are largely unknown in Isatis indigotica Fort.
\end{abstract}

Results: Ten GSLs were identified in I. indigotica, and the dominant GSLs were epiprogoitrin (EPI) and indole-3-methyl GSL (I3M), followed by progoitrin (PRO) and gluconapin (GNA). The total GSL content was highest (over $20 \mu \mathrm{mol} / \mathrm{g}$ ) in reproductive organs, lowest (less than $1.0 \mu \mathrm{mol} / \mathrm{g}$ ) in mature organs, and medium in fresh leaves $(2.6 \mu \mathrm{mol} / \mathrm{g}$ ) and stems $(1.5 \mu \mathrm{mol} / \mathrm{g})$. In the seed germination process, the total GSL content decreased from $27.2 \mu \mathrm{mol} / \mathrm{g}$ (of seeds) to $2.7 \mu \mathrm{mol} / \mathrm{g}$ (on the 120th day) and then increased to $4.0 \mu \mathrm{mol} / \mathrm{g}$ (180th day). However, the content of indole GSL increased rapidly in the first week after germination and fluctuated between $1.13 \mu \mathrm{mol} / \mathrm{g}$ (28th day) and $2.82 \mu \mathrm{mol} / \mathrm{g}$ (150th day). Under the different elicitor treatments, the total GSL content increased significantly, ranging from 2.9-fold (mechanical damage, $3 \mathrm{~h}$ ) to 10.7-fold (MeJA, 6h). Moreover, 132 genes were involved in GSL metabolic pathways. Among them, no homologs of AtCYPT9F2 and ATMAM3 were identified, leading to a distinctive GSL profile in I. indigotica. Furthermore, most genes involved in the GSL metabolic pathway were derived from tandem duplication, followed by dispersed duplication and segmental duplication. Purifying selection was observed, although some genes underwent relaxed selection. In addition, three tandem-arrayed GSL-OH genes showed different expression patterns, suggesting possible subfunctionalization during evolution.

Conclusions: Ten different GSLs with their accumulation patterns and 132 genes involved in the GSL metabolic pathway were explored, which laid a foundation for the study of GSL metabolism and regulatory mechanisms in I. indigotica.

\section{Background}

Isatis indigotica Fort., belonging to Brassicaceae, is widely used in the food, pharmaceutical and cosmetics industries, and its dried leaves and roots, named "Da Qing Ye" and "Ban Lan Gen", have been proven to have antiviral and antifungal effects and to activate the immune system

\footnotetext{
*Correspondence: litao@snnu.edu.cn

${ }^{1}$ Key Laboratory of Medicinal Resources and Natural Pharmaceutical Chemistry (Shaanxi Normal University), The Ministry of Education, Xi'an, Shaanxi 710119, People's Republic of China

Full list of author information is available at the end of the article
}

$[1,2]$. There are numerous compounds in I. indigotica, such as indole alkaloids, lignan metabolites, radix isatidis polysaccharides and glucosinolates. Indigo, mainly extracted from leaves, is a common blue dye extensively used in the textile industry for its safe and environmentally friendly features. Indirubin can be used as antileukemia drug [3-5]. Moreover, the seed oil of this plant has potential value as an edible oil [6].

Glucosinolates (GSLs), known as secondary metabolites in plants, are widely distributed in over 3000 species in 16 families, and are well studied in Arabidopsis thaliana [7]. The structure of GSLs consists of three units, a 
$\beta$-D-thioglucose residue, a sulfide oxime group and a variable side chain group (R-group). To date, many GSLs have been well characterized [8,9] and are thought to be amino acid derivatives broken into three categories, namely, aliphatic, aromatic and indole. Aliphatic GSLs are derived from linear or branched-chain amino acids, including methionine, valine, leucine, isoleucine and alanine. Aromatic GSLs originate from aromatic amino acids, phenylalanine and tyrosine. The precursor amino acid of indole GSLs is tryptophan. The mustard oil bomb system is mainly made up of GSLs and myrosinases, the corresponding $\beta$-glucosidases of GSLs, which play prominent roles in plant-herbivore and plant-pathogen interaction processes [10]. Some isothiocyanates, such as sulforaphane, show good anticancer ability [11]. Brassicaceae vegetables rich in GSLs were proven to be helpful in protecting the liver and other organs [12]. Epigoitrin is the hydrolysate of epiprogoitrin (EPI), a dominant GSL in I. indigotica, and can be used as an antiviral compound $[4,13]$ and allelochemical [14]. Currently, an increasing number of researchers focus on GSLs and their functions.

The biosynthetic pathways of GSLs have been well studied in Arabidopsis [15, 16] and Brassica rapa [17]. Several amino acids, including isoleucine, methionine, phenylalanine and tyrosine, can get elongated to form homo amino acids, and the elongation route of methionine has been well studied [16]. Two branched-chain amino acid aminotransferases (BCAT4 and BCAT6) catalyze methionine and homomethionine into the corresponding 2-oxo acid in the cytoplasm and subsequently transport it into the chloroplast for a three-step cycle. First, methylthioalkylmalate synthase family members (MAMs) condense 2-oxo acid with acetyl-CoA into 2-malate derivatives. MAM1 and MAM3 prefer shortand long- chain GSLs, respectively, and MAM3 usually contributes to the elongation process. Second, isopropylmate isomerases (IPMIs) isomerize 2-malate derivatives and move hydroxyl groups to position 3 . Third, oxidative decarboxylation occurs with the help of isopropylmalate dehydrogenases (IPMDHs), leaving a one-atom-elongated 2-oxo acid in the chloroplast. The cycle can be repeated up to 8 times in Thellungiella halophila [18], where 10-methylsulfinyldecyl GSL was detected. The subsequent transamination requires a chloroplast-localized enzyme, BCAT3, whose products are transported out of the chloroplast for core structure formation, but the corresponding transporter is still unknown [16]. For the elongation of aromatic GSLs, MAM3 was found to accept phenylalanine as a substrate, showing a possible role in aromatic GSL biosynthesis [19].

The formation of the core structure of GSLs is complex. Elongated amino acids as well as other original amino acids can be converted into the corresponding aldoximes, which can be oxidized by cytochrome P450 79 family members (CYP79) [20]. Then, CYP83 can catalyze these aldoximes into activated compounds, i.e., nitrile oxides for tryptophan derivatives and aci-nitro compounds for other derivatives. Next is a glutathione-conjunction step, and sulfur atoms are introduced to activate oximes by glutathione S-transferase family members (GSTs) [21]. $\gamma$-Glutamyl peptidase (GGP) removes $\gamma$-glutamate from the conjunct molecules, which is then converted into thiohydroximates with the help of SUPERROOT 1 (SUR1), an enzyme shared by aliphatic, indole and aromatic GSLs. The following steps are glycosylation and sulfation, charged by UGT74B1 or UGT74C1 and sulfotransferase gene family member 5 (ST5), respectively. Some basic GSLs, namely, methylthioalkyl GSL, benzyl GSL (glucotropaeolin, GTL) and indole-3-methyl GSL (I3M), are biosynthesized at the end of core structure formation.

Side chain modification is beneficial for GSL diversification. The modification of aliphatic GSLs starts from S-oxygenation by $\mathrm{FMO}_{\mathrm{GS}-\mathrm{Ox}}$ gene family members, leading to the synthesis of a methylsulfinylalkyl GSL, such as glucoraphanin (4-methylsulfinylbutyl GSL). Then, alkenylation by alkenyl hydroxalkyl producing (AOP) gene family members produces alkenyl GSL (by AOP2) or hydroxyalkyl GSL (by AOP3) [22]. Other enzymes, such as GSL-OH in ecotype Cvi and GRS1 in radish, are responsible for some particular modifications [23]. On the other hand, the modification of indole GSL is found at positions 1 and/or 4, resulting in the formation of hydroxylated and methoxylated products, such as 4-methoxy-3- indolylmethyl GSL (4MOI3M) and 1-methoxy-3- indolylmethyl GSL (1MOI3M). In addition, sulfonated indole GSL was reported in Isatis spp. [24], indicating a sulfonation process, although the biosynthesis pathway has not been fully described. Moreover, R-hydroxylation (RHO) and S-hydroxylation (SHO) were reported to chirally hydrosylate 2-phenylethyl GSL in Barbarea vulgaris, which affected the structure of aromatic GSLs [25].

Intact GSLs do not show any biological activities until they break into smaller molecules. The breakdown process of GSLs was examined in Arabidopsis [26, 27]. To date, ten enzymes, including $\beta$-glucosidase 23 (BGLU23 or PYK10), BGLU26 (PEN2), BGLU28, BGLU30 and BGLU34-39 (also known as thioglucoside glucohydrolase 1-6, TGG 1-6) can degrade GSLs. TGG1 and TGG2, which are mainly expressed in the aboveground parts of Arabidopsis, function redundantly in abscisic acid-induced and methyl jasmonate-induced stomatal closure [28] and even influence physical defense barrier construction. Likewise, recent studies on a root-specific expressed myrosinase revealed that TGG4 and TGG5 played important roles in auxin biosynthesis and root 
growth regulation [29]. As an atypical myrosinase, PEN2 participates in pathogen defense in Arabidopsis. In addition, some cofactors could be involved in the GSL breakdown process with myrosinases. Nitrile-specifier proteins (NSPs), epithiospecifier proteins (ESPs) and thiocyanateforming proteins (TFPs) can adjust GSL metabolism flow, resulting in the formation of nitriles, epithionitriles and thiocyanate rather than isothiocyanates [30]. On the other hand, myrosinase-binding and myrosinase-association proteins are available to increase the efficacy of glucosinolate breakdown and might be involved in defense against biotic stress [26, 31].

Many transcription factors can regulate GSL biosynthesis in plants. Among them, MYB28, 29, and 76, and MYB34, 51, and 122 can positively regulate aliphatic and indole GSL biosynthesis in Arabidopsis, respectively. MYC2, 3, 4 and 5 can directly interact with MYB proteins, showing redundant functions in response to jasmonic acid. Sulfur limitation 1 (SLIM1) can activate the breakdown process of GSLs under sulfur deficiency and downregulate MYB expression levels [32]. In addition, Dof1.1 and IQ-domain 1 (IQD1) can regulate the expression of GSL metabolism-related genes [33, 34]. Recent studies also verified the functions of CAMTA3, CCA1, FRS7, FRS12 and $H Y 5$ [35, 36], and an epistatic regulation network is still being constructed, indicating the complicated relationships of the transcription factors in the GSL metabolic pathway [37].

Different developmental stages, organs and tissues, as well as different treatments, have different effects on the accumulation and metabolism of GSLs. For example, the seeds and roots of Brassicaceae plants accumulated more GSLs than other organs [38]. Methyl jasmonate (MeJA) and salicylic acid (SA) had distinct impacts on GSL accumulation [39]. The distributions of GSLs were summarized in more than 130 genera [7], showing GSL variations across evolution. GSL profiles have been investigated in Arabidopsis [11], and GSL accumulations were also discussed in B. rapa [40, 41], B. oleracea [42], Raphanus sativus [43], Bunias erucago [44], Isatis spp. [24] and recently in Erysimum spp. [45] and Lepidium graminifolium [46]. However, little is known about GSL accumulation and regulation in I. indigotica [47-50]. Here, the GSL contents at different developmental stages, in different organs and under different treatments were determined, and the related genes were also explored and analyzed in this species.

\section{Results}

\section{Glucosinolate determination in I. indigotica}

The GSLs were investigated by LC-MS/MS on their corresponding desulfo counterparts, considering the results of previous reports $[47,51]$. All the detected GSLs are listed in Table 1, Table S1 and Figs. S1, S2 and S3. Ten GSLs were identified in I. indigotica, and the dominant GSLs were EPI and I3M, followed by progoitrin (PRO) and gluconapin (GNA). In addition, it was speculated that six new indole GSLs could exist; these compounds showed typical GSL characteristics on LC-MS/MS spectra, i.e., sulfide oxime moiety $(\mathrm{m} / z=75)$, neutral loss (198 Da instead of $162 \mathrm{Da}$, because of chloride ion contamination), fragments from desulfurized glycoside aglycone $(m / z=144,146$ and 160$)$ and an even-numbered

Table 1 Detected GSLs in I. indigotica

\begin{tabular}{|c|c|c|c|c|c|c|}
\hline No. & Name & $\begin{array}{l}\text { Relative } \\
\text { molecular weight }\end{array}$ & $\begin{array}{l}\text { Mass after } \\
\text { desulphonation }(\mathrm{m} / \mathrm{z})\end{array}$ & Retention time (min) & $\begin{array}{l}\text { Correction } \\
\text { coefficient }\end{array}$ & Type \\
\hline 1 & Progoitrin & 389 & 309 & 5.3 & 1.09 & aliphatic \\
\hline 2 & Epiprogoitrin & 389 & 309 & 5.8 & 1.09 & aliphatic \\
\hline 3 & Sinigrin (Internal standard) & 359 & 279 & 6.8 & 1 & aliphatic \\
\hline 4 & Gluconapin & 373 & 293 & 10.2 & 1.11 & aliphatic \\
\hline 5 & $\begin{array}{l}\text { 4-hydroxy- } \\
\text { 3-indolylmethyl GSL }\end{array}$ & 464 & 384 & 11.9 & 0.28 & indole \\
\hline 6 & Glucobrassicanapin & 387 & 307 & 13.7 & 0.25 & aliphatic \\
\hline 7 & Glucotropaeolin & 409 & 329 & 14.7 & 0.95 & aromatic \\
\hline 8 & Indolyl-3-methyl & 448 & 368 & 16.8 & 0.29 & indole \\
\hline 9 & $\begin{array}{l}\text { 4-methoxy- } \\
\text { 3-indolylmethyl GSL }\end{array}$ & 478 & 398 & 18.8 & 0.25 & indole \\
\hline 10 & $(R, S)-G l u c o i s a t i s i n$ & 562 & 482 & $20.9(\mathrm{R}) 21.1(\mathrm{~S})$ & 1 & aliphatic \\
\hline 11 & $\begin{array}{l}\text { 1-methoxy- } \\
\text { 3-indolylmethyl GSL }\end{array}$ & 478 & 398 & 23.8 & 0.2 & indole \\
\hline
\end{tabular}

Notes: The retention time is chosen to sequence GSLs in Table 1. All GSLs are grouped into three types, namely aliphatic, aromatic and indole, according to their side chain structures. Correction coefficient is used to eliminate the error in content determination 

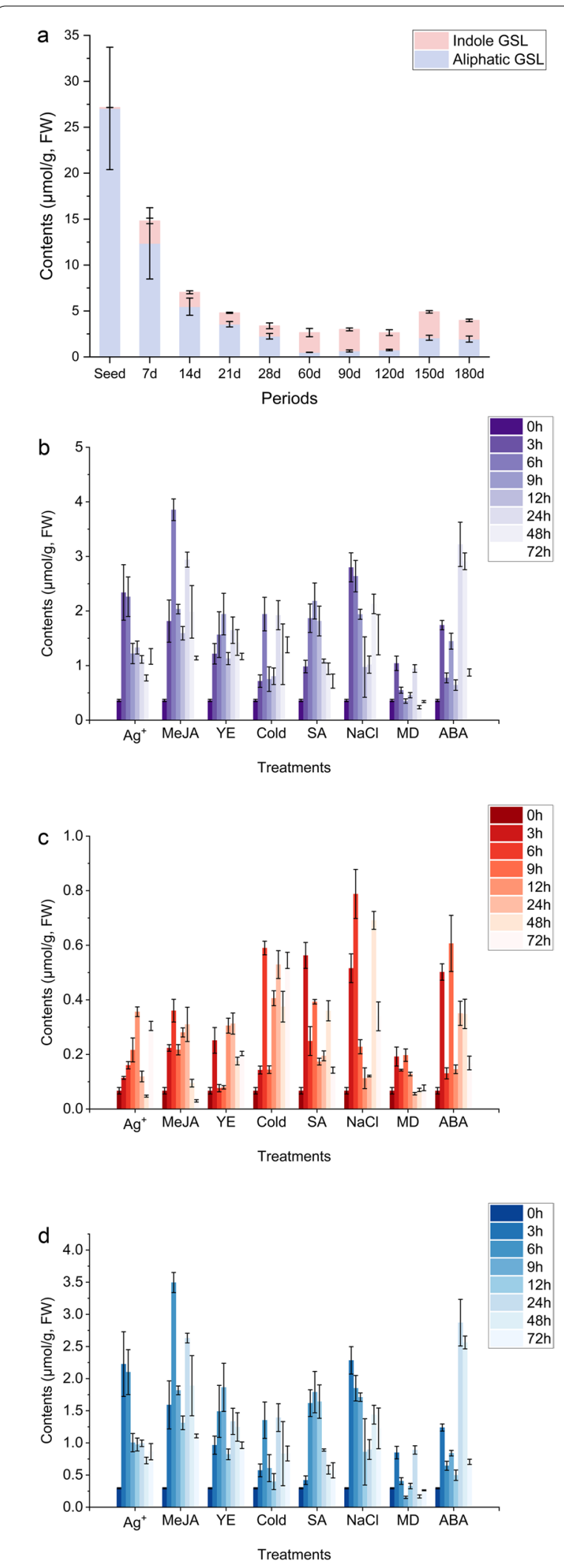

Fig. 1 GSL contents in different developmental periods and responding to the different elicitors. $\mathrm{Ag}^{+}: 10 \mathrm{mM}$ silver nitrate solution; MeJA: $500 \mu \mathrm{M}$ methyl jasmonate solution; YE: $10 \mathrm{~g} / \mathrm{L}$ yeast extraction solution; Cold: $4^{\circ} \mathrm{C}$ treatment; SA: $300 \mu \mathrm{M}$ salicylic acid solution; $\mathrm{NaCl}: 0.1 \mathrm{~mol} / \mathrm{L}$ sodium chloride solution; MD: mechanical damage treatment; ABA: $1 \mathrm{mM}$ abscisic acid solution; a GSL contents in different developmental periods (seeds, 7, 14, 21, 28, 60, 90, 120, 150 and 180 DAG); Red columns show the indole GSL contents, while blue columns represent the aliphatic GSL contents; $\mathbf{b}$ Total GSL contents variations after different elicitor treatments over time $(3,6,9$, 12, 24, 48 and 72 h); c Aliphatic GSL content variations after different elicitor treatments over time; $\mathbf{d}$ Indole GSL content variations after different elicitor treatments over time; Mean \pm SD values $(n=3)$ were shown in each column. The detailed results are listed in Table S2

relative molecular mass $(m / z=384$ or 400$)$ (Fig. S4, [52$55]$ ), but further evidence is still needed.

\section{Glucosinolate content changes in different developmental periods in I. indigotica}

The GSL accumulation patterns during the different developmental periods were measured (Fig. 1a, detailed in Table S2b). The total GSL content was the highest $(27.2 \mu \mathrm{mol} / \mathrm{g}, \mathrm{FW})$ in seeds (Fig. 1a). After germination, the total GSL content decreased sharply until 60 DAG (days after germination) and then increased gradually, with aliphatic GSLs being the main compound. In particular, limited indole GSLs $(0.10 \mu \mathrm{mol} / \mathrm{g})$ were detected in seeds, while aliphatic GSLs contributed to more than 99\% of the total GSL content. In seedlings, indole GSLs remained relatively stable. The levels of some specific GSLs, such as PRO, EPI and GNA, apparently decreased from germination to 60 DAG (Table S2b). In addition, R-glucoisatisin and S-glucoisatisin (combined as glucoisatisin, GIT) were detected before 28 DAG, with a peak value $(0.98 \mu \mathrm{mol} / \mathrm{g})$ at $7 \mathrm{DAG}$. Moreover, indole GSL distribution patterns were also observed, and I3M was not detected in seeds. The indole GSL contents fluctuated between $1.1 \mu \mathrm{mol} / \mathrm{g}$ (28 DAG) and $2.8 \mu \mathrm{mol} / \mathrm{g}(150$ DAG). Three indole GSLs with side-chain modifications, namely, 4-hydroxy-3-indolylmethyl GSL (4OHI3M), $4 \mathrm{MOI} 3 \mathrm{M}$ and $1 \mathrm{MOI} 3 \mathrm{M}$, reached the highest values at 60 $(0.12 \mu \mathrm{mol} / \mathrm{g}), 120(0.38 \mu \mathrm{mol} / \mathrm{g})$ and $150(0.93 \mu \mathrm{mol} / \mathrm{g})$ DAG, respectively. Interestingly, $1 \mathrm{MOI} 3 \mathrm{M}$ showed a similar variable pattern to aliphatic GSLs, and the lowest value $(0.24 \mu \mathrm{mol} / \mathrm{g})$ appeared at $60 \mathrm{DAG}$.

\section{Glucosinolate content changes in different organs in $I$. indigotica}

The GSL contents in ten organs were examined, as shown in Table 2. Reproductive organs were more enriched for GSLs than vegetative organs, followed by roots and the 
Table 2 Glucosinolate contents in different organs in I. indigotica

\begin{tabular}{|c|c|c|c|c|c|c|c|}
\hline Organs & $\begin{array}{l}\text { Total GSLs }(\mu \mathrm{mol} / \mathrm{g} \text {, } \\
\text { FW) }\end{array}$ & $\begin{array}{l}\text { Aliphatic GSLs } \\
(\mu \mathrm{mol} / \mathrm{g}, \mathrm{FW})\end{array}$ & Percentage (\%) & $\begin{array}{l}\text { Indole GSLs }(\mu \mathrm{mol} / \mathrm{g} \text {, } \\
\text { FW) }\end{array}$ & Percentage (\%) & $\begin{array}{l}\text { Aromatic } \\
\text { GSLs }(\mu \mathrm{mol} / \mathrm{g} \text {, } \\
\text { FW) }\end{array}$ & $\begin{array}{l}\text { Percentage } \\
(\%)\end{array}$ \\
\hline Main roots & $10.257 \pm 1.202^{b}$ & $7.418 \pm 0.890^{b}$ & 72.3 & $2.839 \pm 0.312^{c}$ & 27.7 & N.D. & - \\
\hline Lateral roots & $18.053 \pm 1.648^{c}$ & $15.015 \pm 0.857^{c}$ & 83.2 & $3.039 \pm 0.790^{c}$ & 16.8 & N.D. & - \\
\hline Mature stems & $0.392 \pm 0.038^{\mathrm{a}}$ & $0.365 \pm 0.032^{\mathrm{a}}$ & 93.2 & $0.027 \pm 0.0059^{a}$ & 6.8 & N.D. & - \\
\hline Middle stems & $0.736 \pm 0.039^{a}$ & $0.732 \pm 0.039^{a}$ & 99.4 & $0.005 \pm 0.001^{\mathrm{a}}$ & 0.6 & N.D. & - \\
\hline Fresh stems & $1.505 \pm 0.068^{\mathrm{a}}$ & $1.490 \pm 0.066^{\mathrm{a}}$ & 99.0 & $0.016 \pm 0.001^{\mathrm{a}}$ & 1.0 & N.D. & - \\
\hline Mature eaves & $0.429 \pm 0.057^{a}$ & $0.405 \pm 0.056^{\mathrm{a}}$ & 94.5 & $0.024 \pm 0.002^{\mathrm{a}}$ & 5.5 & N.D. & - \\
\hline Fresh leaves & $2.595 \pm 0.215^{a}$ & $2.556 \pm 0.211^{\mathrm{a}}$ & 98.5 & $0.038 \pm 0.004^{a}$ & 1.5 & N.D. & - \\
\hline Buds & $20.629 \pm 1.746^{c}$ & $20.540 \pm 1.727^{c}$ & 99.6 & $0.073 \pm 0.014^{a}$ & 0.3 & $0.016 \pm 0.004^{a}$ & 0.1 \\
\hline Flowers & $22.791 \pm 0.837^{c}$ & $22.124 \pm 0.699^{c}$ & 97.1 & $0.488 \pm 0.084^{\mathrm{ab}}$ & 2.1 & $0.179 \pm 0.054^{b}$ & 0.8 \\
\hline Immature fruits & $21.352 \pm 1.437^{c}$ & $20.254 \pm 1.297^{c}$ & 94.9 & $0.864 \pm 0.090^{b}$ & 4.0 & $0.234 \pm 0.050^{b}$ & 1.1 \\
\hline
\end{tabular}

Note: The data show the GSL contents in different organs. Discrepant lowercase letters represent different significant levels. All data are displayed with means \pm SD values $(n=3)$. N.D. means "not detected"

remaining aerial parts. Few GSLs distributed in mature stems and leaves. Aliphatic GSLs were dominant in all organs, accounting for more than $70 \%$ of the total GSLs. More GSLs were distributed in fresh leaves and stems than in senescent organs. The most abundant GSLs were EPI (from 0.34 to $13.16 \mu \mathrm{mol} / \mathrm{g}$ ) and PRO (from 0.04 to $8.87 \mu \mathrm{mol} / \mathrm{g}$ ), as shown in Table S2c. Interestingly, glucotropaeolin (GTL) and glucobrassicanapin were only detected in reproductive organs, and glucobrassicanapin could barely be detected by LC-MS/MS. Additionally, PRO, EPI and GNA were the three dominant GSLs in the early reproductive growth period, reaching 95\% of the total GSLs and sharing similar distribution patterns. However, the distribution patterns of the other GSLs were diverse. I3M was more abundant in roots, flowers and fruits but less abundant in stems and leaves, and $1 \mathrm{MOI} 3 \mathrm{M}$ was mainly distributed in roots (over $1.5 \mu \mathrm{mol} / \mathrm{g})$.

\section{Glucosinolate content changes under different treatments in I. indigotica}

The effects of eight elicitors on GSL accumulation were investigated (Fig. 1b-d, Table S2d). The results revealed that $\mathrm{MeJA}, \mathrm{NaCl}$ and $\mathrm{ABA}$ had the most remarkable effects on the total GSL accumulations, and the peak contents were 3.85 (10.7-fold compared to control groups, $6 \mathrm{~h}$ ), 2.96 (7.7-fold, $3 \mathrm{~h}$ ) and $3.32 \mu \mathrm{mol} / \mathrm{g}$ (8.9-fold, $24 \mathrm{~h})$, respectively. However, mechanical damage did not have a significant influence, with only a 2.6 -fold change at the peak (3h). For aliphatic GSLs, SA, low temperature, $\mathrm{NaCl}$ and ABA resulted in 8.4-fold (3h), 8.8-fold (6h), 11.7-fold (6h) and 9.1-fold (9h) increases, respectively. Notably, SA, $\mathrm{NaCl}$ and ABA treatments had clear effects on PRO and EPI, and the peak times were 3 (8-fold), 6 (10-fold) and $9 \mathrm{~h}$ (11-fold), respectively. Furthermore, the indole GSL contents increased after $\mathrm{AgNO}_{3}, \mathrm{MeJA}$, $\mathrm{NaCl}$ and $\mathrm{ABA}$ treatments, and the peak values reached $2.23 \mu \mathrm{mol} / \mathrm{g}$ (3h), $3.49 \mu \mathrm{mol} / \mathrm{g}$ (6h), $2.28 \mu \mathrm{mol} / \mathrm{g}$ (3h) and $2.87 \mu \mathrm{mol} / \mathrm{g}(24 \mathrm{~h})$, respectively. The different elicitors had different impacts on I3M, one of the main GSLs, and its contents reached their highest values $(3.01 \mu \mathrm{mol} / \mathrm{g}$ and $2.67 \mu \mathrm{mol} / \mathrm{g}$ ) after $6 \mathrm{~h}$ of MeJA and $24 \mathrm{~h}$ of ABA treatments. In contrast, $\mathrm{AgNO}_{3}$ and $\mathrm{NaCl}$ had obvious impacts on I3M, with peak values $(1.84$ and $1.89 \mu \mathrm{mol} / \mathrm{g})$ found after $3 \mathrm{~h}$. For SA and YE treatment, the contents of I3M reached $1.51 \mu \mathrm{mol} / \mathrm{g}$ and $1.65 \mu \mathrm{mol} / \mathrm{g}$ over $9 \mathrm{~h}$.

\section{Exploration of Glucosinolate metabolic pathways in I. indigotica}

Based on the genome database of I. indigotica from our lab (the raw data in the NCBI database can be accessed with accession number PRJNA612129), the genes involved in GSL biosynthesis and breakdown pathways were explored (Table S3). There were 132 genes involved in the GSL metabolic process (Table 3), of which 70 genes were related to the biosynthesis process, 38 genes played roles in the breakdown process, 2 genes worked as transporters, and 22 genes regulated gene expression as transcription factors. In addition, there were 32 homologous chromosome segments with base deletions and insertions, perhaps due to nonfunctionalization.

Based on the GSL metabolic pathways of Arabidopsis and those from other studies $[16,56,57]$, the GSL metabolic pathway of I. indigotica is shown in Fig. 2. Sixtyeight genes, including core enzyme genes (CYP79 and CYP83), were single-copy genes, while 17 enzymes had two or more functional copies. In particular, 13 functional genes were homologous to AtTGG1 (AT5G26000) or AtTGG2 (AT5G25980), and that number was greater than that in other Brassicaceae plants (Table S4). As 
Table 3 Number of glucosinolate metabolic genes

\begin{tabular}{|c|c|c|c|c|}
\hline Categories & Process & Number of genes & Number of similar sequences & Total \\
\hline \multirow[t]{4}{*}{ Biosynthesis } & Side-chain elongation (SE) & 14 & 2 & 16 \\
\hline & Core structure formation (CF) & 26 & 4 & 30 \\
\hline & Side-chain modification (CM) & 19 & 3 & 22 \\
\hline & Co-substrate pathways (CS) & 11 & 2 & 13 \\
\hline \multirow[t]{2}{*}{ Breakdown } & Myrosinase (MY) & 21 & 10 & 31 \\
\hline & $\begin{array}{l}\text { Co-factor involved in glucosinolate break- } \\
\text { down (CB) }\end{array}$ & 17 & 11 & 28 \\
\hline Transcription factor & & 22 & & 22 \\
\hline Transportation & & 2 & & 2 \\
\hline Total & & 132 & 32 & 164 \\
\hline
\end{tabular}

shown in Fig. 3a, the GSL pathway genes were distributed on all seven pseudochromosomes, revealing a certain concentrated distribution, with no additional clustering. One hypothesis is that the GSL metabolic pathway evolved step by step, and gene recruitment did not depend on proximity. Up to 33 genes were located on Chr04 and Chr06, while 13 genes were located on Chr05. There were 19 pairs (45 genes, Fig. 3) of tandem duplicates, more than any other repeat type (Table 4), implying the importance of tandem repeat events [58]. The genes involved in the GSL breakdown process are shown in Fig. 3b. There were three prominent regions where GSLrelated genes were densely distributed, namely, NSP-like loci, TGG-like loci and MBP-like loci, which were located near each other on Chr04 or Chr06. However, there were some sequences that seemed nonfunctionalized due to base deletions or insertions. In contrast, 5 NSP loci, 5 myrosinase-binding protein (MBP) loci and 11 TGG loci were relatively complete.

The cytochrome P450 family (CYP), 2-oxoglutaratedependent dioxygenase family (2OGD) and MAM genes played important roles in the GSL metabolic pathway, and phylogenetic trees were constructed for I. indigotica and other Brassicaceae species, with Carica papaya and Moringa oleifera as the outgroup species (Fig. 4, Figs. S5, S6 and S7 and Table S5). In terms of GSL profiles [7, 8 ] and the relevant core genes (Fig. 4, Table S5, Figs. S5, S6 and S7), our study results supported that I. indigotica has a close relationship to Sisymbrium irio, Brassica spp. and $R$. sativus. Different GSL profiles existed in different plants. I. indigotica mainly accumulated hydroxyalkenyl GSLs, while Arabidopsis tended to accumulate methylsulfinylalkyl GSLs. Moreover, some genes were absent in I. indigotica, including $M A M 2, M A M 3, C Y P 79 F 2$, UGT74C1, FMO ${ }_{G S-O X} 1 / 3 / 4 / 6 / 7, A O P 3$, BZO1p1, MYB76, $M Y B 115, N S P 3$ and NSP4, based on the genomic data (Table S6, Fig. S8). Among them, MAM3 and CYP79F2 participate in long-chain aliphatic GSL biosynthesis, while $A O P 3$ catalyzes the transition of methylsulfinylalkyl GSLs to hydroxyalkyl GSLs. Furthermore, FMO $_{\text {GS-OX }}$ enzymes could also result in the absence of long-chain aliphatic and hydroxyalkyl GSLs [59].

\section{Selection on genes involved in Glucosinolate metabolism in I. indigotica}

Selection always affects gene evolution in plants. Using the proteins encoded by glucosinolate-related genes in I. indigotica as references, we searched the protein database of 25 other Brassicaceae species by BLASTp, and vice versa. Bidirectional best hits were regarded as homologous genes and used for further analysis (Fig. S6, Table S8). The ParaAT workflow [60] was carried out to calculate nonsynonymous nucleotide substitution rates (Ka), synonymous nucleotide substitution rates (Ks) and their ratios $(\mathrm{Ka} / \mathrm{Ks})$ for gene pairs. The results are shown in Table S7. The GSL pathway was divided into eight groups (Table S3), i.e., side-chain elongation (SE), core structure formation (CF), side-chain modification

\footnotetext{
(See figure on next page.)

Fig. 2 The GSL metabolic pathway of I. indigotica. Numbers in brackets represent the numbers of genes homologous with Arabidopsis; Red, green and blue words or squares represent aliphatic, aromatic and indole GSL metabolism-related genes or products, respectively; Dashed lines indicate the predicted reaction or multiple-step reactions; BCAT: branched-chain amino acid aminotransferase; MAM: methylthioalkylmalate synthase; IPMI: isopropyImalate isomerase; IPMDH: isopropylmalate dehydrogenase; CYP: cytochrome P450 monooxygenase; GST: glutathione S-transferase; SUR: S-alkyl-thiohydroximate lyase; UGT: uridine 5'-diphospho-glucuronosyltransferase; ST: sulphotransferase; FMO: flavin-containing monooxygenase; AOP: alkenyl hydroxyalkyl producing; IGMT: indole glucosinolate O-methyltransferase; TGG: thioglucoside glucohydrolase; PEN2: penetration-resistance gene 2; BGLU: beta glucosidase; APS: adenosine 5'-phosphosulphate; APS: adenosine 5'-phosphosulphate; APK: APS kinase; GSH: glutathione; PAPS: 3'-phospho-adenosine-5'-phosphosulphate; PAP: 3'-phospho-adenosine 5'-phosphate
} 


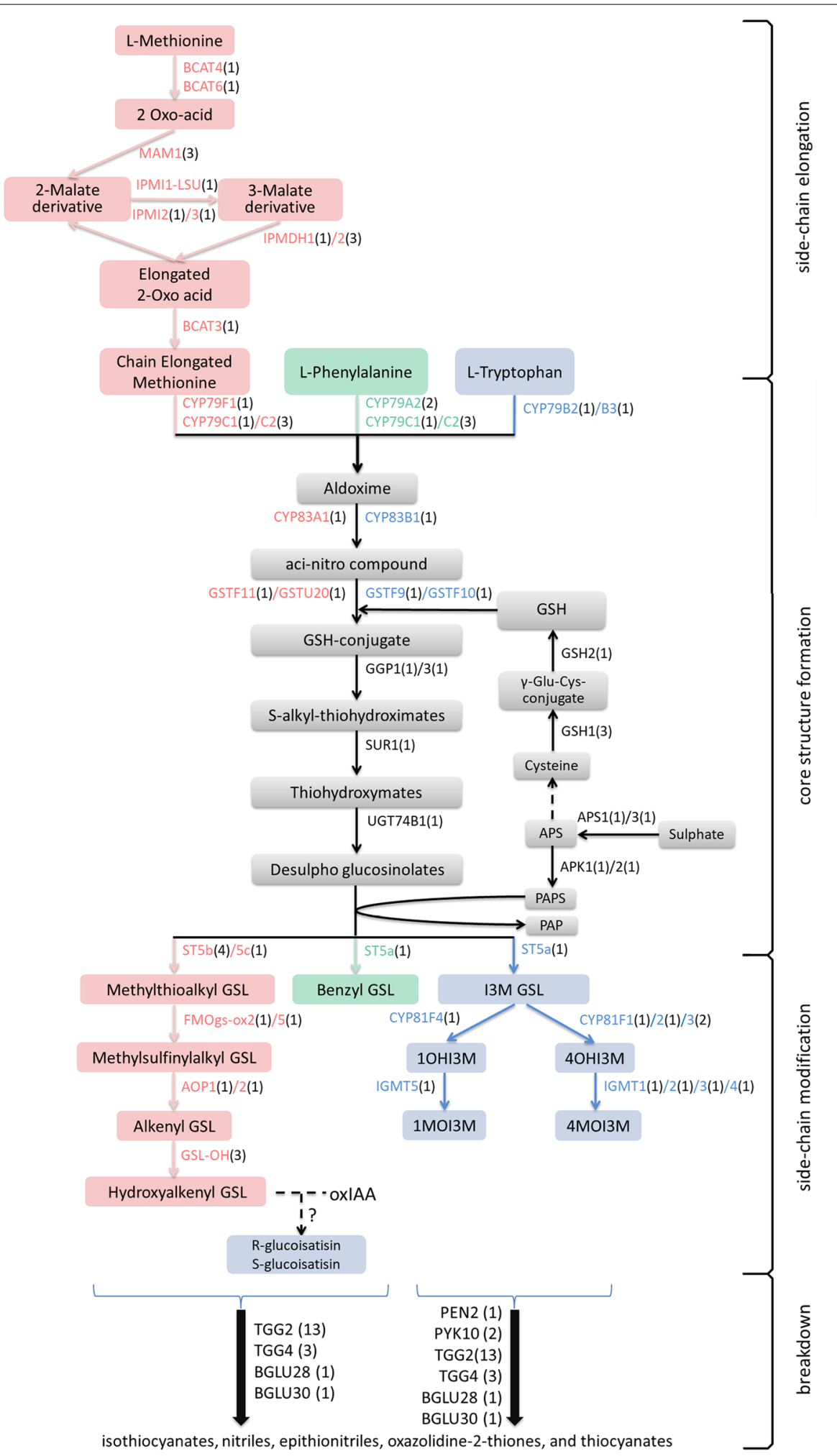

Fig. 2 (See legend on previous page.) 
(SM), cosubstrate pathways (CS), myrosinase (MY), cofactors involved in glucosinolate breakdown (CB), transcription factors (TF) and transportation (TP). As illustrated in Fig. 5, most genes were under selective pressure during evolution. Interestingly, SM, CB and TF processes underwent more relaxed selection than SE, CF and CS processes. Additionally, CF, SM and MY each were divided into subgroups. For CF (Fig. S9a), no significant differences were observed among key enzymes (CYP79 and CYP83) shared between aliphatic and indole GSL biosynthesis (GGP, SUR and UGT) and their respective biosynthetic enzymes (GST and ST5). Nevertheless, a discrepancy in selection pressure was found between the atypical and typical myrosinases (Fig. S9c), as well as between genes involved in aliphatic and indole GSL modifications (Fig. S9b).

\section{Analysis of the key side-chain modification genes related to GSL-OH in I. indigotica}

To understand the expression characteristics of GSLrelated genes, the expression patterns of the aliphatic GSL side chain modification genes were analyzed for nine different organs and seven developmental periods (Fig. 6), using $e I F 2$ and $P P 2 A-4$ as the reference genes [61]. GSL-OH genes could catalyze alkenyl GSLs (i.e., GNA) to hydroxyalkenyl GSLs (i.e., PRO and EPI) and were homologous to AT2G25450. Three GSL-OH genes and two GSL-OH-like genes in tandem arrangement were found in I. indigotica. As shown in Fig. 6, the expression levels of GSL-OH-1 were unstable in different developmental periods, varying from 0.32 - to 1.75 -fold, compared to the samples at 7 DAG, while the levels of GSL-OH-2 were relatively low at 21 DAG (0.10-fold), 90 DAG (0.24-fold) and 150 DAG (0.21-fold). GSL-OH-3 (over 3.39-fold) and GSL-OH-like 1 (over 4.76-fold) exhibited higher expression levels after 120 DAG, while GSL-OH-like 2 had the highest expression level (2.81-fold) at 180 DAG. Significant expression differences were also found in different organs. GSL-OH-1 was mainly expressed in aboveground organs, while GSL-OH-2 was expressed in roots. GSL-OH-3 was highly expressed in flowers (3.78-fold) but showed lower levels in other organs (from 0.45 -fold in lateral roots to 1.66-fold in fresh stems compared with main roots). In addition, GSL-OH-like 1 and GSL-OH-like 2 were mainly expressed in reproductive organs (over 96.33-fold) and leaves (over 8.75-fold). In short, the expression levels of five genes homologous to GSL-OH showed differences in different organs and developmental periods, which could lead to the subtle regulation of hydroxyalkenyl GSL biosynthesis in I. indigotica.

Generally, the ratio of the nonsynonymous substitution rate $(\mathrm{Ka})$ to the synonymous substitution rate $(\mathrm{Ks})$ reflects the selection pressure of paired genes, and the Ks value can be used to estimate divergence time [62]. We calculated Ka and Ks between GSL-OH-1/GSL-OH-2 and GSL-OH-2/GSL-OH-3 by KaKsCalculator 2.0 [63]. Furthermore, the divergence time of these two gene pairs was estimated using the formula $\mathrm{T}=\mathrm{Ks} / 2 \lambda$, where $\mathrm{T}$ means divergence time and $\lambda$ (mutation rate) was set as $1.5 \times 10^{-8}$ substitutions/site/year [64]. The results are listed in Table 5. GSL-OH-1 and GSL-OH-3 derived from GSL-OH-2 approximately 3.5-2.8 million years ago (Pliocene). The Ka/ Ks ratios of GSL-OH-1/GSL-OH-2 and GSL-OH-2/GSL$\mathrm{OH}-3$ were above 0.5 (Table 5), displaying weak positive selection during evolution [65].

\section{Discussion}

The diversity in Glucosinolate accumulation in I. indigotica GSLs exhibit strong anti-insect, antipathogen and immunoregulatory effects in plants [7], and their side-chain structures affect their biological functions. For instance, 1-methyethyl GSL and 1-methylpropyl GSL improved the resistance of Arabidopsis to Erwinia carotovorum [66], while $4 \mathrm{MOI} 3 \mathrm{M}$ activated the innate immune system [67, 68]. Thus, there could exist some mechanisms for GSL diversification $[67,68]$.

In this study, the dominant GSLs in I. indigotica were EPI and I3M, followed by PRO and GNA, which was different from those in other Isatis spp. [24], in which I3M and GNA showed higher contents. A recent study of GSL profiles in dried roots of I. indigotica identified 16 GSLs, including 12 aliphatic GSLs, 2 aromatic GSLs and 2 indole GSLs [50]. In our study, there were 10 identified GSLs, while six potential new GSLs still needed to be further investigated (Fig. S4). The different experimental materials (dried roots vs. seedlings), the different dosages $(6 \mathrm{~kg}$ vs. $0.2 \mathrm{~g})$ and the different plant lines could contribute to the different research results. Both of these results suggest that more aliphatic GSLs and fewer aromatic and

(See figure on next page.)

Fig. 3 Chromosome locations of GSL metabolism genes. a Numbers on the left show the location (Mb) of genes on pseudochromosomes; Arrows on the right are the relative direction; Genes with gradient green rectangle background represent side-chain elongation process, core structure formation process, side-chain modification process and co-substrate process, respectively; Light red rectangles represent myrosinases, and dark red shapes represent co-factor; Yellow rectangles mean transcription factors; Similar sequences of biosynthetic genes and breakdown genes are filled with light and dark grey, respectively; Boxes of transportation genes are painted with blue; Segments filled in orange on the pseudochromosome are enlarged in b. Chr: pseudochromosome. b The linear distributions of GSL breakdown genes on Chr04 and Chr06. Light or dark red squares represent genes with complete ORF; Grey squares mean nonfunctionalization fragments; the distance is shown above lines 


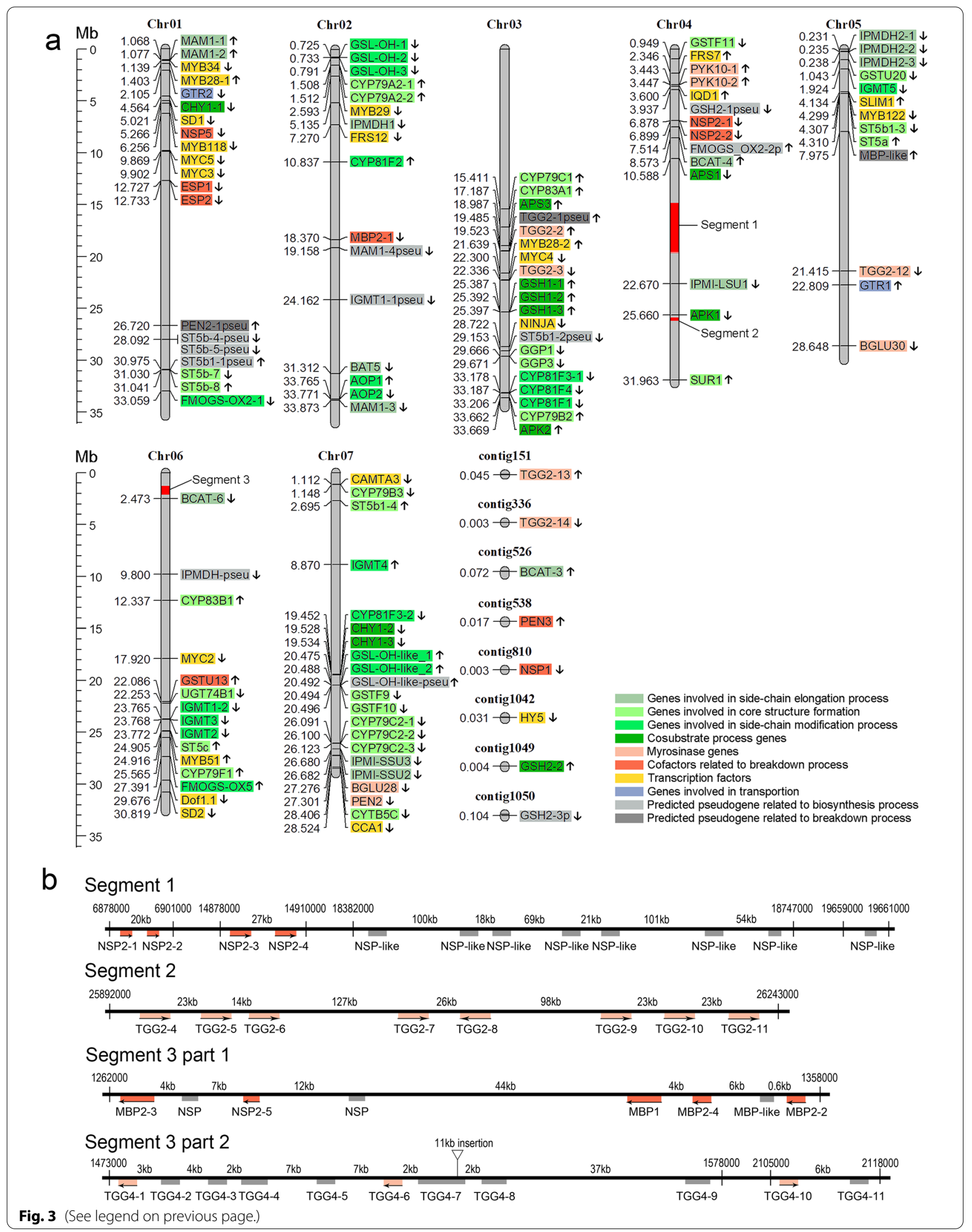


Table 4 Duplication type and the corresponding number of glucosinolate metabolic genes

\begin{tabular}{lll}
\hline Duplication type & $\begin{array}{l}\text { Gene numbers in GSLs } \\
\text { metabolic pathway }\end{array}$ & $\begin{array}{l}\text { Gene numbers } \\
\text { around the whole } \\
\text { genome }\end{array}$ \\
\hline Singleton & 0 & 3224 \\
Dispersed & 37 & 19,317 \\
Proximal & 17 & 1770 \\
Tandem & 45 & 3242 \\
WGD or segmental & 33 & 7226 \\
Total & 132 & 34,779 \\
\hline
\end{tabular}

indole GSLs were present in dried roots, but more indole GSLs were found in seedlings and may enrich the GSL profiles in I. indigotica.

Based on our results, the aliphatic GSL contents initially decreased and then increased during the development process in I. indigotica, similar to what occurs in Arabidopsis [69], Brassica oleracea var. italica [70] and Armoracia rusticana [71]. GSLs contain considerable amounts of sulfur and are mainly involved in primary metabolic processes, with some breakdown products functioning as allelochemicals [14], which might be the reason for the reduction in aliphatic GSL contents. Indole GSLs accumulated dramatically during the germination period, with contents $(2.45 \mu \mathrm{mol} / \mathrm{g}$ at 7 DAG) that increased by 22 times as high as that in seeds $(0.10 \mu \mathrm{mol} / \mathrm{g})$, which was different from the results for Isatis tinctoria L., in which GSLs accumulated slowly during the first month [49]. Moreover, the dominant GSL was sulfoglucobrassicin in I. tinctoria, which was different from that in I. indigotica. In addition, the distribution patterns of GSLs in I. indigotica were similar to those in Arabidopsis [38], except that fresh leaves accumulated more GSLs than fresh stems, which supports the current theory on the optimal distribution of defense substances [72]. It was noteworthy that $(R, S)$-GIT was only detected before 28 DAG (Table S2b) and was lacking in immature fruits, indicating its roles in the early development of seedlings of $I$. indigotica, as it might accumulate in later stages.

For MeJA treatment, the contents of indole GSLs increased 12 -fold $(3.49 \mu \mathrm{mol} / \mathrm{g}$ at $6 \mathrm{~h})$, and aliphatic GSLs only increased 5.4-fold $(0.36 \mu \mathrm{mol} / \mathrm{g})$, similar to Brassica rapa ssp. chinensis, in which 8 -fold and 3-fold increases in aliphatic and indole GSLs were found [73]. Nevertheless, the contents of aliphatic GSLs were unchanged under MeJA treatment in Arabidopsis, B. oleracea var. italica [74] and Eruca sativa [39]. In addition, $\mathrm{NaCl}$ significantly induced the accumulation of aliphatic and indole GSLs in I. indigotica, and the peak values appeared after $3-6 \mathrm{~h}$ and $48 \mathrm{~h}$, respectively. Moreover, the continuous cold treatment exhibited a significant effect on aliphatic GSL accumulation. The transcriptome data indicated that the genes involved in glucosinolate and tryptophan metabolic pathways could take part in the vernalization process in Pak choi [75]. When considering both the different developmental periods and organs, there could also be some GSL profile changes when the $I$. indigotica seedlings overwintered.

\section{Genes involved in Glucosinolate metabolic pathways in I. indigotica}

A total of 132 genes involved in GSL metabolic processes were identified in $I$. indigotica. It seemed that $M A M 3, A O P 3$ and $C Y P 79 F 2$ were missing in I. indigotica compared to Arabidopsis. Similar elements were missing in Aethionema, Brassica and Raphanus, indicating that these genes were genus-specific (Table S6, Fig. S5, S6 and S7). Gene duplication and subsequent subfunctionalization are important for creating and expanding biochemical diversity in plants [58]. Here, 68 genes were single-copy, including the core enzymes CYP79B, CYP79F and CYP83. Moreover, MAM1 and GSL-OH had three functional copies, which could adjust metabolite flow. A recent report showed that CYP79C gene family members could catalyze six different amino acids to their corresponding oximes in transgenic tobacco [20]. Nine out of 26 Brassicaceae species had one or two CYP79C1 copies, while 66 genes homologous to AtCYP79C2 were found in these 26 species, suggesting expansion during evolution (Table S5b, Fig. S6). It was shown that there were two CYP79C gene family members in the ancestor of Brassicaceae according to the phylogenetic trees, but why most species lost $C Y P 79 C 1$ is worth discussing.

Thirteen TGG1/2 and three TGG4/5 homologous loci were found, with some pseudogene fragments neglected in I. indigotica (Fig. 3b, Table S3). These genes could code proteins with complete domains, including TFNEP and ITENG (Fig. S10). NSP and MBP, acting as cofactors in the GSL breakdown process, had many similar fragments. Chromosome replications can occur after gene duplication due to their linear arrangement, and several genes could be nonfunctionalized to avoid biochemical disturbance in plants [76]. The number of TGG genes was examined in other Brassicaceae species (Table S4). Sixteen and fifteen TGG1/2 genes were discovered in $B$. oleracea and $B$. nigra, respectively, while 18 TGG4/5 genes were discovered in Camelina sativa. However, when taking domain completeness into consideration, it was found that only 6,4 , and 11 of the genes maintained their complete functional domains. Nevertheless, these species went through whole genome duplication/triplication 


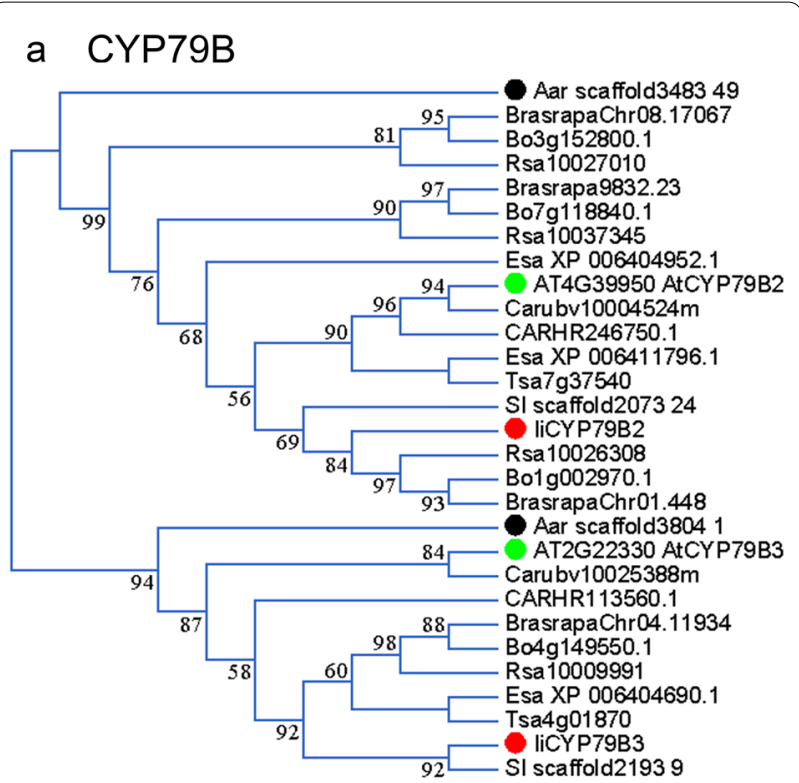

b CYP79F

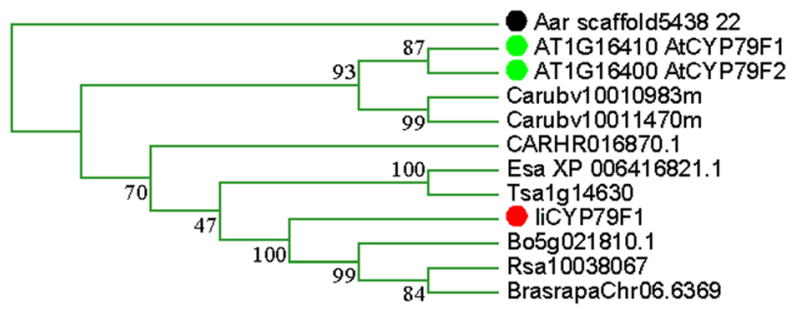

c CYP83A

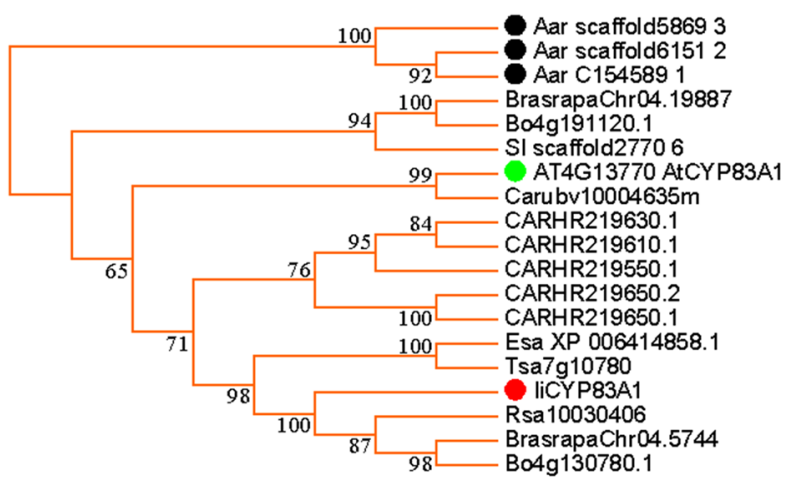

d CYP83B

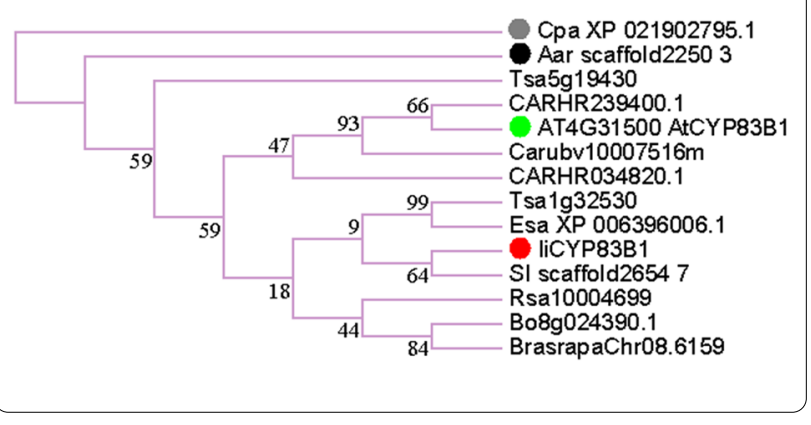

Fig. 4 Phylogenetic trees of GSL metabolic pathway core genes. a CYP79B; b CYP79F; c CYP83A; d CYP83B; Different species are distinguished by different colours, green for Arabidopsis, red for I. indigotica, black for Aethionema arabicum (the basal species of Brassicaceae), and grey for C. papaya (a closely related species of Brassicaceae). All phylogenetic trees are constructed by FastTree 2.1 using 1000 bootstrap replicates. Detailed information can be found in Fig. 56 and Table S5

separately, and thus, it was clear that I. indigotica could have more GSL breakdown-related genes, even though their actual biological functions are unknown. It is worth noting that more functional fragment replications could exist in I. indigotica, especially considering the size of the genome. In addition, we used all-vs-all BLAST to identify the orthologs of 13 TGG2 and 3 TGG4 genes (Table S6), and TGG2-13 and TGG4-10 were thought to be the most likely ancestor genes. Interestingly, neither of them were in the dense segments in which most GSL breakdown genes were located (Fig. 3), and further analysis showed that these dense segments had no synteny among $I$. indigotica, Megadenia pygmaea and Arabidopsis (data not shown), suggesting an insertion event during genome evolution. Recent genome sequencing of Scutellaria baicalensis demonstrated that 6 loci on pseudochromosome 9 could encode the $C H S 2$ gene, which is involved in root-specific flavone biosynthesis [77]. Similar results were also found in Senna tora, where 15 CHS-L genes were tandemly arranged [78]. Moreover, studies on the $\beta$-glucosidase (BGLU) [79] and BURP domain gene families [80] also suggested multiplied tandem duplication events in Morinda officinalis and Bruguiera gymnorrhiza, respectively. The balance between gene birth and gene death is key to duplication events. Gene family expansion enhanced gene expression levels and influenced the balance of metabolic flux. The subsequent regulation of expression could lead to three different fates for repeated genes, namely, neofunctionalization, subfunctionalization or nonfunctionalization [76], which is beneficial to environmental adaptation, such as glyphosate resistance in Kochia scoparia [81]. As more genome data are released, the significance behind this phenomenon will be revealed.

Brassicaceae species share the same side-chain elongation (SE) and core structure formation (CF) processes in the GSL biosynthesis pathway [8]. In contrast, side-chain modification (SM) has expanded the GSL profiles of different species, leading to at least 89 GSLs being dispersed over the Brassicales [9]. Thus, relaxed selection is beneficial to the catalysis reaction on different GSL structures (Fig. 5). Similarly, aliphatic GSLs show significant differences in their side chains, such 


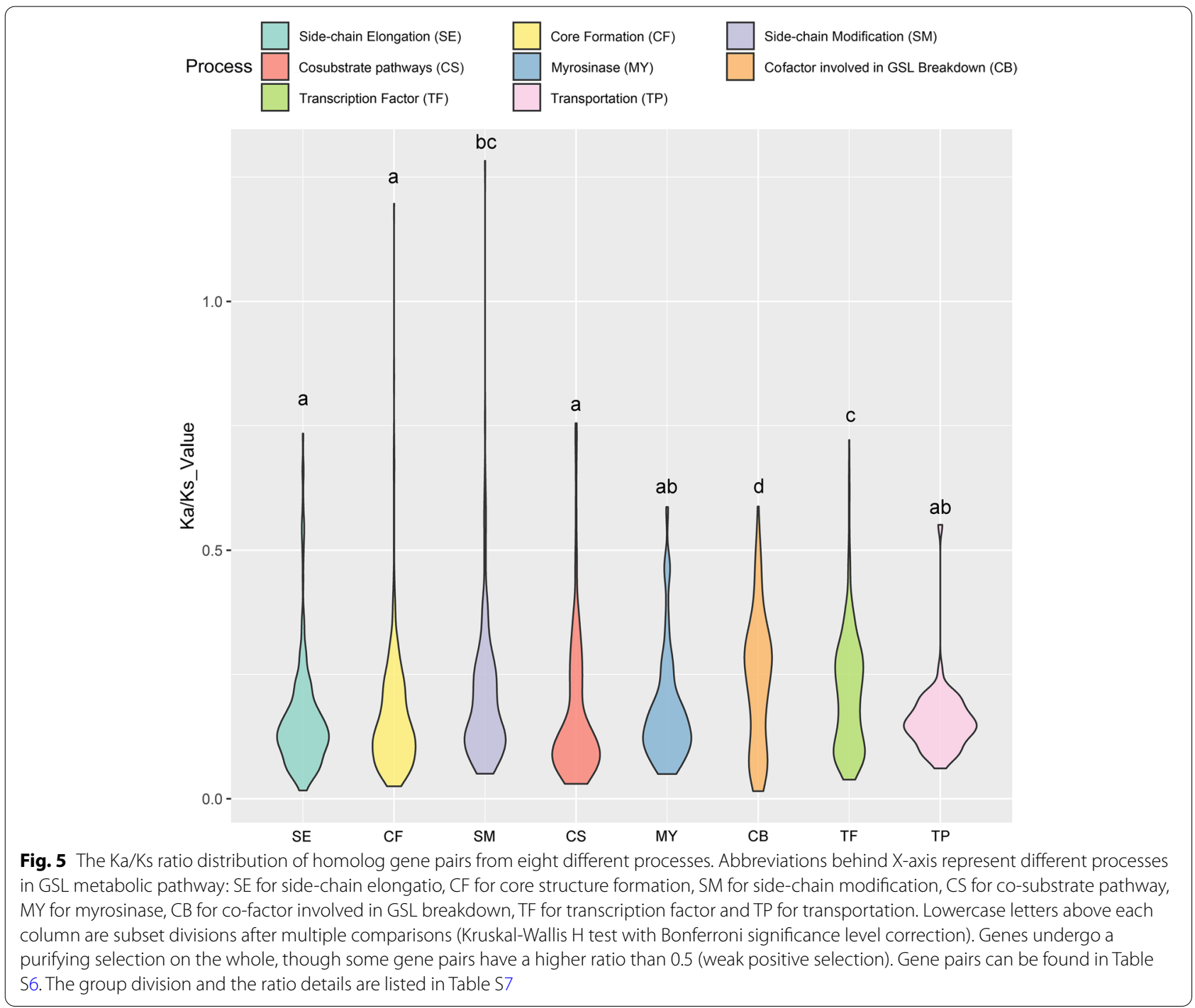

as the length of the side chain and saturation degree of carbon molecules; however, indole GSLs experience hydroxylation and methoxylation at fixed positions in most species [8], requiring a stronger selective pressure during evolution (Fig. S9b, with a median less than 0.12). Another interesting finding was the weaker selective pressure on typical myrosinases than atypical myrosinases (Fig. S9c). We identified the copy numbers of different myrosinases among 26 Brassicaceae species, and the numbers of PEN2 and BGLU28 homologs were lower than those of $T G G 1 / 2 / 3$ and $T G G 4 / 5 / 6$, two kinds of typical myrosinases. In particular, PEN2, a gene involved in the innate immune response to pathogens [68], remained single-copy in 20 out of 26 species (also one functional copy in $I$. indigotica), even in $B$. oleracea and $B$. nigra, two species that underwent a recent whole triplication event. Thus, the discrepancy in the $\mathrm{Ka} / \mathrm{Ks}$ ratio between typical and atypical enzymes might reflect relaxed selection on duplicated genes, potentially leading to neofunctionalization during evolution $[82,83]$.

Relationships between gene expression and Glucosinolate accumulation in I. indigotica

A pair of chiral isomers, goitrin and epigoitrin, showed differences in their activities [4, 13, 84]. Goitrin and epigoitrin are derived from progoitrin and epiprogoitrin, respectively [85]. Goitrin results in a goitrogenic reaction, but epigoitrin does not [86]. The GSL-OH homologous genes GSL-OH-1, GSL-OH-2 and GSL-OH-3 were found in I. indigotica. We tried to determine whether the different genes could catalyze one of the isomers, similar to $\mathrm{RHO}$ and SHO in Barbarea vulgaris [25]. Association analysis (Table S8) revealed that there were no apparent 

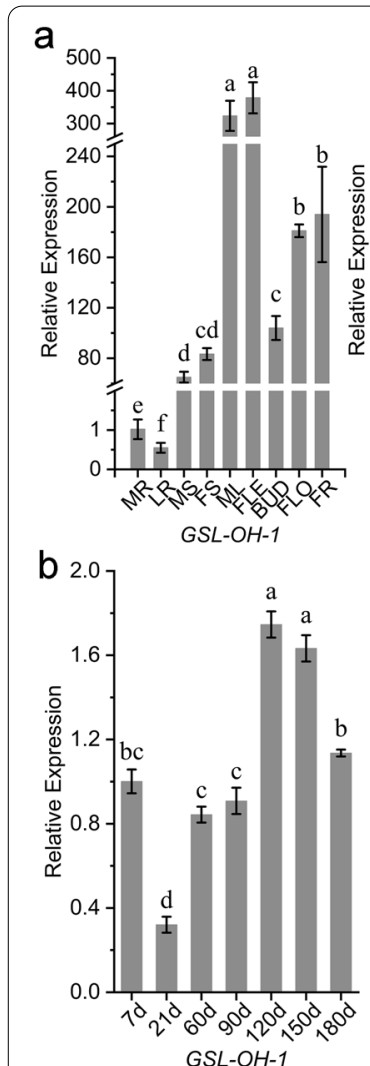
$60,90,120,150$ and 180 DAG); The determination results of the main roots and 7 DAG seedlings were chosen as the reference points, respectively. Each lowercase letter represents a distinctively significant level
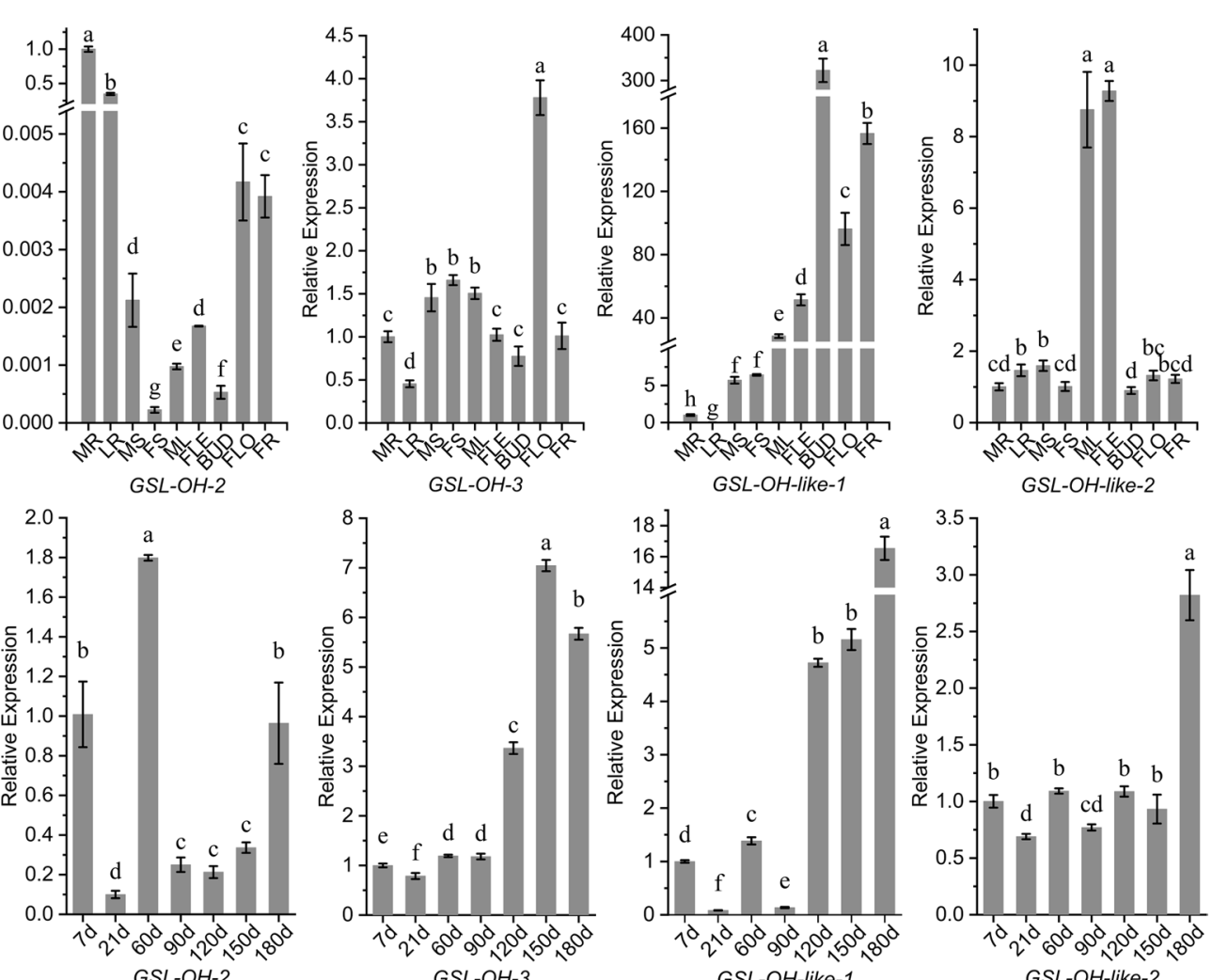

Table 5 Nonsynonymous substitution rate and synonymous substitution rate between specific GSL-OH genes

\begin{tabular}{lllll}
\hline Gene pairs & $\begin{array}{l}\text { Nonsynonymous substitution } \\
\text { rate (Ka) }\end{array}$ & $\begin{array}{l}\text { Synonymous substitution rate } \\
\text { (Ks) }\end{array}$ & Ka/Ks & $\begin{array}{l}\text { Divergent } \\
\text { time (Million } \\
\text { Years) }\end{array}$ \\
\hline GSL-OH-1/GSL-OH-2 & 0.05525 & 0.10331 & 0.53480 & 3.44 \\
GSL-OH-2/GSL-OH-3 & 0.05390 & 0.08470 & 0.63636 & 2.82 \\
\hline
\end{tabular}

correlations between the gene expression levels and GSL accumulation, suggesting that the corresponding proteins encoded by those genes could catalyze PRO and EPI synthesis. Nevertheless, the transport of GSLs and breakdown of epiprogoitrin could not be fully excluded. To some extent, subfunctionalization could be considered since GSL-OH homologous genes showed organ-specific expression patterns (Fig. 6).

\section{Methods}

\section{Plant materials and treatments}

Seeds of I. indigotica purchased from Shaanxi GeoAuthentic Medicinal Plant Co. Ltd. (Xi'an, China) were cultivated in round pots (three seedlings per pot) in the greenhouse $\left(25 \pm 2{ }^{\circ} \mathrm{C}, 16 \mathrm{~h}\right.$ light $/ 8 \mathrm{~h}$ dark) until reaching different developmental stages and under different elicitor treatments; plants were watered every $2-3$ days and maintained at $60-80 \%$ relative humidity of the soil. Different organs, namely, main roots, lateral roots, mature stems, middle stems, fresh stems, mature leaves, fresh leaves, buds, flowers and immature fruits, when flowers and fruits appeared simultaneously (in April, 2018), were samples from plants growing in the experimental field to provide the different organ samples (Table S9). For GSL content determination at different developmental stages, whole plants at 7, 14, 21, 28, 60, 90, 120, 150 and 180 days 
old were collected. The elicitor treatments, including MeJA $(500 \mu \mathrm{mol} / \mathrm{L})$, silver nitrate solution $\left(\mathrm{AgNO}_{3}\right.$, $10 \mathrm{mmol} / \mathrm{L})$, yeast extract (YE, $10 \mathrm{~g} / \mathrm{L}), \mathrm{SA}(300 \mu \mathrm{mol} / \mathrm{L})$, sodium chloride solution $(\mathrm{NaCl}, 0.1 \mathrm{~mol} / \mathrm{L})$ and abscisic acid $(\mathrm{ABA}, 1 \mathrm{mmol} / \mathrm{L})$, were conducted by foliage spraying. In addition, low temperature $\left(4^{\circ} \mathrm{C}\right)$ and mechanical damage (punching holes on leaves) were also used. All the plant materials were collected and put in liquid nitrogen immediately and then stored at $-80^{\circ} \mathrm{C}$ for further analyses.

\section{Glucosinolate extraction and HPLC analysis}

The extraction method was used with few modifications [87]. The plant materials were ground thoroughly in liquid nitrogen and then briefly put into a microtube with $5.0 \mathrm{~mL}$ precooled methanol/water $(85: 15, \mathrm{v} / \mathrm{v})$ for deactivating myrosinase. After vortexing and standing for $30 \mathrm{~min}$, the microtube was placed on a shaker for another $30 \mathrm{~min}$. Thereafter, the extract solution was centrifuged at $4{ }^{\circ} \mathrm{C}$ and $8000 \mathrm{rpm}$ for $5 \mathrm{~min}$. And $40 \mu \mathrm{L}$ of internal standard solution (sinigrin, $1.0 \mathrm{mg} / \mathrm{mL}$, Sigma Sci. Co. Ltd.) was added to the extract solution and then stored at $-20^{\circ} \mathrm{C}$. Subsequently, the stored solution was slowly added to the DEAE Sephadex A-25 anion-exchange column (1.0 mL, Solarbo, Beijing) and then washed with $2.0 \mathrm{~mL}$ of sodium acetate solution $(0.02 \mathrm{~mol} / \mathrm{L})$ three times and $2.0 \mathrm{~mL}$ of ultrapure water twice. After that, $500 \mu \mathrm{L}$ of sulfatase solution $(2.2 \mathrm{U} / \mathrm{mL})$ was added to fill the whole column, and the column was kept at $35^{\circ} \mathrm{C}$ for $16 \mathrm{~h}$ for complete desulfurization. Finally, the desulfo-GSLs were washed with $500 \mu \mathrm{L}$ of ultrapure water three times.

The analysis of GSLs was performed on LC-2030 high-performance liquid chromatography (HPLC) equipment (Shimadzu, Japan) with an Inersil ODS-3 column $(150 \mathrm{~mm} \times 3.0 \mathrm{~mm}$ i.d., $3.0 \mu \mathrm{m}$, GL Sciences, Japan). The program was set as follows: from 0 to $17 \mathrm{~min}, 98 \%$ ultrapure water and $2 \%$ acetonitrile (Merck, Germany), which gradually changed to 80 and $20 \%$, respectively, and held on for $3 \mathrm{~min}$. Then, the percentage of ultrapure water was reduced to $70 \%$ in the next $5 \mathrm{~min}$. Next, the column was washed with pure acetonitrile for $6 \mathrm{~min}$ and returned to $2 \%$ in the final step. The flow speed was set to $0.4 \mathrm{~mL} /$ min with a column temperature of $30^{\circ} \mathrm{C}$, each injection was $10 \mu \mathrm{L}$, and the UV detector wavelength was set to $229 \mathrm{~nm}$. The peak areas were integrated to calculate the GSL contents by the internal standard method, and the correction factors were determined according to ISO 9167-1 [88]. The correction factors for other GSLs were 0.25 for indole and 1 for aliphatic GSLs according to Grosser and Van Dam (2017) [89].
Table 6 LC-MS/MS conditions

\begin{tabular}{ll}
\hline Items & Parameters \\
\hline Gas Temp & $300^{\circ} \mathrm{C}$ \\
Gas Flow & $10 \mathrm{~L} / \mathrm{min}$ \\
Nebulizer & $45 \mathrm{psi}$ \\
Sheath Gas Temp & $350^{\circ} \mathrm{C}$ \\
Sheath Gas Flow & $11 \mathrm{~L} / \mathrm{min}$ \\
Capillary & $3000 \mathrm{~V}(+) / 3000 \mathrm{~V}(-)$ \\
Nozzle Voltage & $500 \mathrm{~V}(+) / 500 \mathrm{~V}(-)$ \\
\hline
\end{tabular}

The following formula was applied to calculate GSL contents:

$$
w_{\text {measure }}=\frac{k_{\text {measure }}}{m_{\text {sample }}} \times \frac{A_{\text {measure }}}{A_{I S}} \times \frac{c_{I S} \times V_{I S}}{M_{I S}} \times 10^{3}
$$

$w_{\text {measure }}, k_{\text {measure }}$ and $A_{\text {measure }}$ indicate the content $(\mu \mathrm{mol} / \mathrm{g})$, relative correlation coefficient and HPLC peak area of a measured GSL. $A_{I S}, c_{I S}, V_{I S}$ and $M_{I S}$ represent the HPLC peak area of the internal standard (sinigrin), concentration of the internal solution $(\mathrm{mg} / \mathrm{mL})$, volume of the internal standard solution $(\mathrm{mL}$, here $0.040 \mathrm{~mL})$ and relative molecular mass of the internal standard (sinigrin, $\mathrm{M}=397.5 \mathrm{~g} / \mathrm{mol}$ ), respectively. $m_{\text {sample }}$ is the weight of raw materials used for extraction.

\section{Glucosinolate identification and determination}

An Agilent 1200 HPLC system (Agilent, USA) with electrospray ionization coupled to an Agilent 6460 triple quadruple mass spectrometer (LC-ESI-MS/MS) was used to confirm the structures of the GSLs. The HPLC conditions were the same as those mentioned in the previous section, and the mass conditions are listed in Table 6. Compounds with $m / z=75$ and featuring [M-G-H $]^{-}$molecular ion peaks were selected as candidate compounds $[90,91]$. The positive ion peak, such as $[\mathrm{M}-\mathrm{G}+\mathrm{H}]^{+}$, was used for identification [51, 92]. For MS/ MS conditions, the fragmentor voltage was optimized by approximately $1 / 3$ of the molecular weight, and the collision energy number was set to approximately $1 / 15$ of the given molecular weight.

\section{Identification of Glucosinolate metabolism-related genes}

The genome of I. indigotica was independently sequenced on the Pac-Bio platform by our group, and the raw data were submitted to the National Center for Biotechnology Information (NCBI) database under BioProject PRJNA612129. The details of the assembly and annotation will be reported in another article. For short, the reads were filtered and then assembled with the help of Canu [93], WTDBG [94] and Falcon [95]. Optimization 
of the first-round assembly was performed by Quickmerge [96]. The Illumina sequencing result was merged to polish the assembly before using a high-throughput chromosome conformation capture technique (Hi-C) library, which was used to perform chromosome anchoring. Three strategies, namely, ab initio prediction, homologous prediction and transcriptome-guided prediction, were used for gene model fitting.

The GSL metabolism-related genes from Arabidopsis and B. rapa were obtained from TAIR [56] and BrassicaDB [57], respectively. A library was built, and the BLASTn program [97] was applied to identify the homologous genes in I. indigotica with a threshold of $1 \mathrm{e}-5$. The sequences were corrected according to the transcriptome dataset to remove incorrect splicing predictions. Moreover, PFAM [98] and CDD [99] searches were conducted to ensure that the genes included conserved domains. The ExPASy tool [100] and Euk-mLoc2 [101] were used to predict the physical and chemical properties and protein sublocalization. MapChart 2.3.2 [102] was used to draw the distribution figure of GSL metabolism-related genes, while DNAMAN (Lynnon Corporation, Canada) was chosen to draw the figure of the sequence alignment results.

\section{Analysis of genes related to Glucosinolate metabolism}

The duplicate_gene_classifier package in MCScanX [103] was used to determine the duplication type for glucosinolate metabolic genes. All-vs-all BLASTp [97] was performed for the I. indigotica genes using the parameters "blastp -evalue 1e-20 -outfmt 6 -num_alignments 6", and the matchings with the genes themselves were removed. Then, the duplication type was determined using default parameters in the duplicate_gene_classifier package.

The identified glucosinolate metabolic genes from $I$. indigotica and the reported genes from Arabidopsis were used as queries to perform BLASTp searches in 24 Brassicaceae species protein databases (Table S6). Then, the best two hits from each species were BLASTp searched against all the proteins from I. indigotica and Arabidopsis. The bidirectional matching pairs were selected and regarded as possible homologous gene pairs from different species and were used as input for the ParaAT workflow [60] to obtain nonsynonymous nucleotide substitution rates $(\mathrm{Ka})$ and synonymous nucleotide substitution rates (Ks). The result was filtered to remove gene pairs with a $p$ value greater than 0.05 . Violin plots were drawn with the help of the ggplot2 package in R 4.1.1 [104].

Phylogenetic tree and orthologous gene analysis indicated that GSL-OH-2 was the progenitor of GSL-OH-1 and GSL-OH-3 (Table S6, Fig. S5). Thus, Ka and Ks values were calculated between these two pairs using
KaKsCalculator 2 software [63]. Divergence time was estimated according to the formula $\mathrm{T}=\mathrm{Ks} / 2 \lambda$, in which $\mathrm{T}$ was the divergence time (Mya) and $\lambda$ was the substitution rate of nucleotides (rate/site/year). The $\lambda$ value was set to $1.5 \times 10^{-8}$, which is a frequently used mutation rate in Brassicaceae [64].

\section{Construction of the phylogenetic tree}

The sequences of GSL metabolism-related genes were downloaded from the TAIR, BrassicaDB, NCBI [105], Ensemble [106] and JGI [107] websites in October 2021. All sequences were aligned by the Muscle program [108] with default parameters. The maximum likelihood method using the Jones-Taylor-Thornton (JTT) substitution model was applied for phylogenetic tree construction by FastTree 2.1.11 with the following parameters: "-pseudo -spr 4 -mlacc 3 -slownni -slow -gamma -no2nd" [109]. Phylogeny tests were verified by the bootstrap method with 1000 replications. All results were visualized by MEGA 7.0 [110].

\section{Gene expression analysis}

To investigate the expression patterns of GSL metabolism-related genes, qRT-PCR was performed with TB Green ${ }^{\circledR}$ Premix Ex Taq ${ }^{\text {TM }}$ Kit (Takara, Dalian, China) on a Roche LightCycler ${ }^{\circledR} 96$ platform using a GSL side-chain modification gene $(G S L-O H)$ as the example. The plant material was the same batch that was previously used in GSL determination; samples were ground into powder in liquid nitrogen and then RNA was extracted according to the manual of the HiPure Plant RNA Mini Kit (Magen Technology, Guangzhou, China). The first chain of cDNA was generated by PrimeScript ${ }^{\mathrm{TM}}$ RT Master Mix (Takara, Dalian, China). The primers are shown in Table 7, with IiPP2A-4 and IieIF2 selected as the reference genes for the different periods and 5 tissues, respectively [61]. A three-step procedure was designed for qRT-PCR detection as follows: premelting at $95^{\circ} \mathrm{C}$ for $30 \mathrm{~s}, 45$ cycles of melting at $95^{\circ} \mathrm{C}$ for $10 \mathrm{~s}$, annealing at $55^{\circ} \mathrm{C}$ for $10 \mathrm{~s}$, and chain extension at $72^{\circ} \mathrm{C}$ for $20 \mathrm{~s}$, followed by signal acquisition of melting curves at $65^{\circ} \mathrm{C}$ for $60 \mathrm{~s}$ and $97^{\circ} \mathrm{C}$ for $1 \mathrm{~s}$. The $2^{-\Delta \Delta \mathrm{Ct}}$ method was used to calculate relative gene expression, with the expression level of the main root (for organs) or 7 DAG (for periods) set as 1 for reference. Each reaction was performed in three individual wells $(n=3)$, and ANOVA was used for statistical analysis (details in "Statistical Methods").

\section{Statistical methods}

Every experiment was performed in triplicate with three biological replicates $(n=3)$, including GSL content determination and qRT-PCR analysis of gene expression. The GSL contents and gene expression levels are presented 
Table 7 Primer sequences of the selected GSL side-chain modification genes in I. indigotica

\begin{tabular}{|c|c|c|c|c|}
\hline Primer Name & Forward Primer $\left(5^{\prime}-3^{\prime}\right)$ & Reverse Primer $\left(5^{\prime}-3^{\prime}\right)$ & $\begin{array}{l}\text { Length of } \\
\text { Products (bp) }\end{array}$ & Related Gene Name \\
\hline elF2 & TACCAGTGGCTCGCTTGAC & CAACCAAAGCAAATGACGTACTC & 117 & elF2 \\
\hline PP2A-4 & GAATGCCTGCGAAAGTATGG & TCCTAATGTTGTCAAGGGTCTC & 151 & PP2A-4 \\
\hline 18849-1 & CATATTCCATAACCCGCAGG & GTTACTGTAATACTTCACCAGCTGT & 312 & GSL-OH-1 \\
\hline $18849-2$ & CCTAAACCTTCCTCGGTGGT & CGTCTTTAAGCTCCGCAACA & 106 & GSL-OH-2 \\
\hline 7910 & GCTGGTGAAGTATAGCAGTAACTC & CGCAACCCTAAAGCTTCTGAT & 207 & GSL-OH-3 \\
\hline 13981 & ATTACTACCCGCCTTGTCCA & CGGTTCTTCGCCTCTGTTC & 228 & GSL-OH-like-1 \\
\hline Tri14631 & GGGCTCTTCTCGTCAACCT & GCGTGTACTCAGTGACGGTAG & 251 & GSL-OH-like-2 \\
\hline
\end{tabular}

as the means \pm standard errors (SEs), and they were assessed with one-way analysis of variance (ANOVA), followed by a Bonferroni correction for multiple tests. The significance levels $(p<0.05)$ are distinguished by different lowercase letters. For $\mathrm{Ka} / \mathrm{Ks}$ ratio analysis, the Kruskal-Wallis $\mathrm{H}$ test (nonparametric test) was conducted, and a Bonferroni correction was used to adjust the $p$ value (originally set as 0.05 for significance levels). The results of gene expression and the content determinations of progoitrin (PRO) and epiprogoitrin (EPI) were analyzed by Pearson's correlation analysis. All statistical methods were performed by SPSS 22.0.

\section{Conclusions}

In this study, GSL profiles and accumulation patterns in I. indigotica were studied. Ten GSLs were identified, including 5 aliphatic GSLs, 4 indole GSLs and 1 aromatic GSL, with the dominant GSLs being EPI, I3M and PRO. The total GSL contents varied across different development periods, organs, and elicitor treatments, indicating variable GSL accumulation. The reproductive organs accumulated more GSLs, and MeJA induced a 10.7-fold change after $6 \mathrm{~h}$ of treatment. A total of 132 genes involved in GSL metabolic processes were explored, and the divergence of the metabolic genes could lead to GSL profile differences. Relaxed selection was observed in side-chain modification genes, cofactors involved in GSL breakdown and transcription factors belonging to GSL metabolic pathways. The expression pattern of tandemly duplicated genes, the most common type of GSL-related gene, suggested neofunctionalization and subfunctionalization during evolution when the GSL-OH gene family was considered, while pseudogenes indicated nonfunctionalization during gene evolution. In conclusion, our study is the first to show GSL variations under different conditions and the metabolic pathways in I. indigotica, laying a firm foundation for the study of the accumulation and regulation of GSLs.

\section{Abbreviations}

GSL(s): Glucosinolate(s); PRO: Progoitrin; EPI: Epiprogoitrin; GNA: Gluconapin; I3M: Indole-3-methyl GSL; GIT: Glucoisatisin; FW: Fresh weight; DAG: Day(s) after germination; h: hour(s); 2OGD: 2-oxoglutarate-dependent dioxygenase; NSP: Nitrile-specifier proteins; BGLU: $\beta$-glucosidase; TGG: Thioglucoside glucohydrolase; MBP: Myrosinase-binding protein.

\section{Supplementary Information}

The online version contains supplementary material available at https://doi. org/10.1186/s12870-022-03455-6.

Additional file 1: Figure S1. HPLC Chromatogram $(229 \mathrm{~nm})$ results of typical samples in I. indigotica. (a) Seeds (b) 14 DAG (c) Roots (d) $48 \mathrm{~h}$ low temperature treatment (e) Buds (f) $3 \mathrm{~h}$ MeJA treatment. Numbers represent: 1. desulpho-progoitrin (PRO); 2. desulpho-epiprogoitrin (EPI); 3. desulpho-sinigrin (SIN, internal standard); 4. desulpho-gluconapin (GNA); 5. desulpho-4-hydroxy-3-indolylmethyl GSL (4OHI3M); 7. desulphoglucotropaeolin (GTL); 8. desulpho-Indolyl-3-methyl (I3M); 9. desulpho4-methoxy-3-indolylmethyl GSL (4MOI3M); 10. desulpho-R,S-glucoisatisin (GIT); 11. desulpho-1-methoxy-3-indolylmethyl GSL (1MOI3M).

Additional file 2: Figure S2. The molecular fragments of mass spectrum under negative mode. Y-axis represents ion intensity, while numbers on $X$-axis are the mass-to-charge ratio $(\mathrm{m} / \mathrm{z})$. GSL name and corresponding retention time are shown on the upper right corner of every figure and the unit of the latter one is minute (min).

Additional file 3: Figure S3. The results of neutral loss of mass spectrum under negative mode. Y-axis represents ion intensity, while numbers on $X$-axis are the mass-to-charge ratio $(\mathrm{m} / \mathrm{z}$ ). All neutral loss mass (198Da or $162 \mathrm{Da}$ ) and the mass-to-charge ratio of each desulpho GSLs are shown on the upper right corner of every figure.

Additional file 4: Figure S4. The mass spectrum images of six uncharacterized GSLs. Y-axis represents ion intensity, while numbers on $X$-axis are the mass-to-charge ratio $(\mathrm{m} / \mathrm{z})$. GSL name is shown on the upper right/left corner of every figure. (a) The fragments of complete desulpho molecules under negative mode (b) The neutral loss results under negative mode (c) The fragments of desulphurizated glycoside aglycone under positive mode.

Additional file 5: Figure S5. Phylogenetic trees of $A O P$ (belonging to subgroup 20 of $20 G D$ gene family) and GSL-OH (belonging to subgroup 31 of 20GD gene family). Three 20GD genes from Oryza sativa (http:// rice.plantbiology.msu.edu/) are chosen as outgroup sequences. Different branches are distinguished with colors. And green, red, pink, yellow, black and gray circles represent sequences of Arabidopsis, I. indigotica, Megadenia pygmaea, Barbarea vulgaris, A. arabicum and O. sativa, respectively. Some sequences are removed because of skeptical alignments.

Additional file 6: Figure S6. Phylog enetic trees of certain CYP gene family members. Sequences of CYP51G in I. indigotica are chosen as global outgroups, where tree roots are put. CYP81D and CYP71AN members from Arabidopsis and I. indigotica are set to be out groups of CYP81 and CYP83, 
respectively. Coloured circles represent sequences from specific species: green for Arabidopsis, red for I. indigotica, pink for M. pygmaea, black for A. arabicum and gray for Carica papaya or Moringa oleifera (two relatives of Brassicaceae). Some sequences are removed because of skeptical alignments.

Additional file 7: Figure S7. Phylogenetic trees of certain MAM-IPMS gene family members. Two genes coding isopropylmalate synthase (IPMS) from Oryza sativa (http://rice.plantbiology.msu.edu/) are chosen as outgroup sequences. Different branches are distinguished with colours. And green, red, pink, black and gray circles represent sequences of Arabidopsis, I. indigotica, M. pygmaea, A. arabicum and Carica papaya or $O$. sativa, respectively. Some sequences are removed because of skeptical alignments.

Additional file 8: Figure S8. An overview of homologous gene pairs identified in this study. Green cells represent the existence of gene pairs contrary to grey cells, which mean failure in identify homolog pairs. The raw data can be checked in Table S6. (A) Overview of gene pairs in I. indigotica (B) Overview of gene pairs in Arabidopsis.

Additional file 9: Figure S9. Ka/Ks ratio comparison between different subgroups in GSL metabolic pathway. The subgroup division and other details are given in Table S7. Significance level is set as 0.05 under MannWhitney $U$ test. ${ }^{*},{ }^{* *}$ and ${ }^{* * *}$ represent $p<0.05,0.01$ and 0.001 , respectively. (a) Comparison within three subgroups in GSL core structure formation. (b) Comparison between genes involved in aliphatic and indole GSL side-chain modification. (c) Comparison between atypical and typical myrosinases.

Additional file 10: Figure S10. The sequence alignment of beta-thioglucoside glucohydrolase proteins in Arabidopsis and I. indigotica. The colours of key motif regions are inverted to emphasize them. It shows that two motifs (motif 1 for acid/base catalyst and motif 2 for nucleophile) are all complete in beta-thioglucoside glucohydrolase proteins of I. indigotica, suggesting their ability to work as glycosidase.

Additional file 11: Table S1. LC-MS/MS fragment results of desulpho-GSLS.

Additional file 12: Table S2. The GSL accumulations in I. indigotica for the different periods, organs and treatments. All the data are shown as average contents \pm standard deviation $(n=3)$. Lowercase letters behind the content data are used to indicate the significant levels. N.D.: Not detected.

Additional file 13: Table S3. The identified genes and subcellular localization results. The lists are in an alphabetic arrangement.

Additional file 14: Table S4. Identified TGG genes in 26 different Brassicaceae species. (a) Number of myrosinase gene homologs in 26 Brassicaceae species. (b) Homologous sequence names of myrosinase genes in 26 Brassicaceae species.

Additional file 15: Table S5. Homologous sequences of AOP, GSL-OH, CYP79, CYP81F, CYP83, MAM and IPMS genes in 26 Brassicaceae species.

Additional file 16: Table S6. Homolog gene pairs identified. Green is the background colour of cells, including the homologous genes. The bidirectional best hits are used as homologous pairs here, noting some may not be true orthologs with each other. (a) Identified orthologs of glucosinolate-related genes of I. indigotica in 25 Brassicaceae species (b) Identified orthologs of glucosinolate-related genes of Arabidopsis in 25 Brassicaceae species.

Additional file 17: Table S7. Raw data of Ka/Ks ratio calculation results. The ratio was coloured to show the variation tendency. Source genes are from I. indigotica, and query genes from other Brassicaceae species. Eight processes were divided according to the gene functions in glucosinolate metabolic pathways. For subgroup division, CYP79 and CYP83 are thought to be key enzymes in GSL biosynthesis. GGP, SUR and UGT74B are shared with both aliphatic and indole GSL biosynthesis processes, named "common genes". Different members of GST and ST5 are linked to different GSL formation, and were grouped together. Atypical myrosinases include BGLU28, BGLU30, PEN2 and PYK10, contrast to typical myrosinase TGGs. For side-chain modification, FMO, AOP and GSL-OH take their parts in aliphatic GSL modification, while CYP81F and IGMT modify indole ring in the nature.

Additional file 18: Table S8. Pearson association analysis between the gene expression levels and GSL contents. The significant correlation is marked with an asterisk behind the number.

Additional file 19: Table S9. Selection criteria for samples of ten organs.

Additional file 20: Supplementary Data 1. Protein sequences of $A O P$, and GSL-OH, used for phylogenetic tree construction in this study. This is the source file for Fig. S5. Detailed information can be found in Table S5b.

Additional file 21: Supplementary Data 2. Protein sequences of CYP79, CYP81F and CYP83 used for phylogenetic tree building in this study. This is the source file for Fig. S6. Detailed information can be found in Table S5C.

Additional file 22: Supplementary Data 3. Protein sequences of MAM and IPMS used for phylogenetic tree building in this study. This is the source file for Fig. S7. Detailed information can be found in Table S5d.

\section{Acknowledgements}

Professor Zhezhi Wang is thanked for advices on the genomic data analysis. Professor Cuiqin Li and Dr. Yaya Huang are thanked for the spectrometry data analysis.

\section{Authors' contributions}

TZ: Conceptualization, Methodology, Formal analysis, Investigation, Resources, Writing - Original Draft, Visualization. RL: Methodology, Investigation. JZ and ZW: Resources, Investigation, Revises. TG: Methodology, Visualization. MQ: Resources, Investigation, Data Curation. XH: Methodology. YW: Investigation, Data Curation, Visualization. SY: Resources. TL: Conceptualization, Writing Review \& Editing, Supervision, Project administration. All authors read and approved the final manuscript.

\section{Funding}

This work was supported by Natural Science Foundation of Shaanxi Province (2019JM-352), the Social Development Science and Technology R\&D program of Shaanxi Province (2016SF-390) and the National students'innovation and entrepreneurship training program (\$202010718202). The funders: Review, Editing, Supervision.

\section{Availability of data and materials}

The datasets supporting the conclusions of this article are included within the article and its additional files.

Raw sequencing data were deposited in the Sequencing Read Achive database in NCBI (Accession ID: PRJNA612129),

and predict sequences in this study were submitted to GenBank in NCBI with available accession number listed in Table S3.

\section{Declarations}

\section{Ethics approval and consent to participate}

All methods were in compliance with relevant institutional, national, and international guidelines and legislation.

\section{Consent for publication}

Not applicable.

\section{Competing interests}

The authors declared that they have no conflicts of interest to this work, including (but are not limited to) political, personal, religious, ideological, academic, and intellectual competing interests.

\section{Author details}

${ }^{1}$ Key Laboratory of Medicinal Resources and Natural Pharmaceutical Chemistry (Shaanxi Normal University), The Ministry of Education, Xi'an, Shaanxi 710119, People's Republic of China. ${ }^{2}$ National Engineering Laboratory for Resources Development of Endangered Crude Drugs in Northwest China, College of Life Sciences, Shaanxi Normal University, Xi'an, Shaanxi 
710119, People's Republic of China. ${ }^{3}$ Shaanxi Engineering Research Centre for Conservation and Utilization of Botanical Resources, Xi'an Botanical Garden of Shaanxi Province (Institute of Botany of Shaanxi Province), Xi'an, Shaanxi 710000, People's Republic of China.

Received: 16 May 2021 Accepted: 3 February 2022 Published online: 22 February 2022

\section{References}

1. Shin EK, Kim DH, Lim H, Shin H-K, Kim J-K. The anti-inflammatory effects of a methanolic extract from Radix isatidis in murine macrophages and mice. Inflammation. 2010;33:110-8. https://doi.org/10. 1007/s10753-009-9164-9.

2. Zhou W, Zhang X-Y. Research progress of Chinese herbal medicine Radix isatidis (Banlangen). Am J Chin Med. 2013;41:743-64. https:// doi.org/10.1142/S0192415X1350050X.

3. Wang X, Xue Y, Li Y, Liu F, Jin Q. Effects of Isatis root polysaccharide in mice infected with $\mathrm{H} 3 \mathrm{~N} 2$ swine influenza virus. Res Vet Sci. 2018;119:91-8. https://doi.org/10.1016/j.rvsc.2018.04.012.

4. Luo Z, Liu LF, Wang XH, Li W, Jie C, Chen H, et al. Epigoitrin, an alkaloid from Isatis indigotica, reduces $\mathrm{H} 1 \mathrm{~N} 1$ infection in stress-induced susceptible model in vivo and in vitro. Front Pharmacol. 2019;10:78. https://doi. org/10.3389/fphar.2019.00078.

5. Zhang L, Chen J, Zhou X, Chen X, Li Q, Tan H, et al. Dynamic metabolic and transcriptomic profiling of methyl jasmonate treated hairy roots reveals synthetic characters and regulators of lignan biosynthesis in Isatis indigotica Fort. Plant Biotechnol J. 2016;14:2217-27. https://doi. org/10.1111/pbi.12576.

6. LiT, Qu XY, Zhang QA, Wang ZZ. Ultrasound-assisted extraction and profile characteristics of seed oil from /satis indigotica Fort. Ind Crop Prod. 2012;35:98-104. https://doi.org/10.1016/j.indcrop.2011.06.013.

7. Fahey JW, Zalcmann AT, Talalay P. The chemical diversity and distribution of glucosinolates and isothiocyanates among plants. Phytochemistry. 2001;56:5-51. https://doi.org/10.1016/S0031-9422(00)00316-2.

8. Blaževic I, Montaut S, Burcul F, Olsen CE, Burow M, Rollin P, et al. Glucosinolate structural diversity, identification, chemical synthesis and metabolism in plants. Phytochemistry. 2020;169:112100. https://doi. org/10.1016/j.phytochem.2019.112100.

9. Agerbirk N, Hansen CC, Kiefer C, Hauser TP, Ørgaard M, Asmussen Lange $\mathrm{CB}$, et al. Comparison of glucosinolate diversity in the crucifer tribe Cardamineae and the remaining order Brassicales highlights repetitive evolutionary loss and gain of biosynthetic steps. Phytochemistry. 2021;185:112668. https://doi.org/10.1016/j.phytochem.2021.112668.

10. Stauber EJ, Petrissa K, Maike van O, Birgit V, Tim J, Markus P, et al. Turning the 'mustard oil bomb' into a 'cyanide bomb': aromatic glucosinolate metabolism in a specialist insect herbivore. PLoS One. 2012;7:e35545. https://doi.org/10.1371/journal.pone.0035545.

11. Lee YR, Chen M, Lee JD, Zhang J, Lin S, Fu TM, et al. Reactivation of PTEN tumor suppressor for cancer treatment through inhibition of a MYCWWP1 inhibitory pathway. Science. 2019;364:eaau0159. https://doi.org/ 10.1126/science.aau0159.

12. Paul S, Geng CA, Yang TH, Yang YP, Chen J, jun. Phytochemical and health-beneficial progress of turnip (Brassica rapa). J Food Sci. 2019;84:19-30. https://doi.org/10.1111/1750-3841.14417.

13. Nie L, Wu Y, Dai Z, Ma S. Antiviral activity of Isatidis Radix derived glucosinolate isomers and their breakdown products against influenza a in vitro/ovo and mechanism of action. J Ethnopharmacol. 2020;251:112550. https://doi.org/10.1016/j.jep.2020.112550.

14. Galletti S, Bernardi R, Leoni O, Rollin P, Palmieri S. Preparation and biological activity of four epiprogoitrin myrosinase-derived products. J Agric Food Chem. 2001;49:471-6. https://doi.org/10.1021/jf000736f

15. Sonderby IE, Geuflores F, Halkier BA. Biosynthesis of glucosinolates gene discovery and beyond. Trends Plant Sci. 2010;15:283-90. https:// doi.org/10.1016/j.tplants.2010.02.005.

16. Harun S, Abdullah-Zawawi M-R, Goh H-H, Mohamed-Hussein Z-A. A comprehensive gene inventory for glucosinolate biosynthetic pathway in Arabidopsis thaliana. J Agric Food Chem. 2020;68:7281-97. https:// doi.org/10.1021/acs.jafc.0c01916.
17. Wang H, Wu J, Sun S, Liu B, Cheng F, Sun R, et al. Glucosinolate biosynthetic genes in Brassica rapa. Gene. 2011;487:135-42. https://doi.org/10. 1016/j.gene.2011.07.021.

18. Pang Q, Chen S, Li L, Yan X. Characterization of glucosinolate-myrosinase system in developing salt cress Thellungiella halophila. Physiol Plant. 2009;136:1-9. https://doi.org/10.1111/j.1399-3054.2009.01211.x.

19. Petersen A, Hansen LG, Mirza N, Crocoll C, Mirza O, Halkier BA. Changing substrate specificity and iteration of amino acid chain elongation in glucosinolate biosynthesis through targeted mutagenesis of Arabidopsis methylthioalkylmalate synthase 1. Biosci Rep. 2019;39. https://doi. org/10.1042/BSR20190446.

20. Wang C, Dissing MM, Agerbirk N, Crocoll C, Halkier BA. Characterization of Arabidopsis CYP79C1 and CYP79C2 by glucosinolate pathway engineering in Nicotiana benthamiana shows substrate specificity toward a range of aliphatic and aromatic amino acids. Front Plant Sci. 2020;11:57. https://doi.org/10.3389/fpls.2020.00057.

21. Piślewska-Bednarek M, Nakano RT, Hiruma K, Pastorczyk M, SanchezVallet A, Singkaravanit-Ogawa S, et al. Glutathione transferase U13 functions in pathogen-triggered glucosinolate metabolism. Plant Physiol. 2018;176:538-51. https://doi.org/10.1104/pp.17.01455.

22. Kliebenstein DJ, Lambrix VM, Reichelt M, Gershenzon J, Mitchell-Olds T. Gene duplication in the diversification of secondary metabolism: tandem 2-oxoglutarate-dependent dioxygenases control glucosinolate biosynthesis in Arabidopsis. Plant Cell. 2001;13:681-93. https://doi.org/ 10.1105/tpc.13.3.681.

23. Kakizaki T, Kitashiba H, Zou Z, Li F, Fukino N, Ohara T, et al. A 2-oxoglutarate-dependent dioxygenase mediates the biosynthesis of glucoraphasatin in radish. Plant Physiol. 2017;173:1583-93. https://doi.org/ 10.1104/pp.16.01814.

24. Comlekcioglu N. Bioactive compounds and antioxidant activity in leaves of endemic and native Isatis spp in Turkey. Brazilian Arch Biol Technol. 2019;62:e19180330. https://doi.org/10.1590/1678-4324-20191 80330.

25. Liu TJ, Zhang XH, Yang HH, Agerbirk N, Qiu Y, Wang HP, et al. Aromatic glucosinolate biosynthesis pathway in Barbarea vulgaris and its response to Plutella xylostella infestation. Front Plant Sci. 2016;7:83. https://doi.org/10.3389/fpls.2016.00083.

26. Wittstock U, Burow M. Glucosinolate breakdown in Arabidopsis: mechanism, regulation and biological significance. Arab B. 2010;8:e0134. https://doi.org/10.1199/tab.0134.

27. Zhang L, Kawaguchi R, Morikawa-Ichinose T, Allahham A, Kim S-J, Maruyama-Nakashita A. Sulfur deficiency-induced glucosinolate catabolism attributed to two $\beta$-glucosidases, BGLU28 and BGLU30, is required for plant growth maintenance under sulfur deficiency. Plant Cell Physiol. 2020;61:803-13. https://doi.org/10.1093/pcp/pcaa006.

28. Ahuja I, Kissen R, Hoang L, Sporsheim B, Halle KK, Wolff SA, et al. The imaging of guard vells of thioglucosidase (tgg) mutants of Arabidopsis further links plant chemical defence systems with physical defence barriers. Cells. 2021;10. https://doi.org/10.3390/cells10020227.

29. Fu L, Wang M, Han B, Tan D, Sun X, Zhang J. Arabidopsis myrosinase genes AtTGG4 and AtTGG5 are root-tip specific and contribute to auxin biosynthesis and root-growth regulation. Int J Mol Sci. 2016;17. https:// doi.org/10.3390/ijms17060892.

30. Kuchernig JC, Burow M, Wittstock U. Evolution of specifier proteins in glucosinolate-containing plants. BMC Evol Biol. 2012;12:127. https://doi. org/10.1186/1471-2148-12-127.

31. Kayum MA, Nath UK, Park J-I, Hossain MR, Kim H-T, Kim H-R, et al. Glucosinolate profile and Myrosinase gene expression are modulated upon Plasmodiophora brassicae infection in cabbage. Funct Plant Biol. 2021;48:103-18. https://doi.org/10.1071/FP19278.

32. Henning F, Tamara G. Update on the role of R2R3-MYBs in the regulation of glucosinolates upon sulfur deficiency. Front Plant Sci. 2014;5:626. https://doi.org/10.3389/fpls.2014.00626.

33. Frerigmann $\mathrm{H}$, Gigolashvili T. MYB34, MYB51, and MYB122 distinctly regulate indolic glucosinolate biosynthesis in Arabidopsis thaliana. Mol Plant. 2014;7:814-28. https://doi.org/10.1093/mp/ssu004.

34. Song S, Huang H, Wang J, Liu B, Qi T, Xie D. MYC5 is involved in jasmonate-regulated plant growth, leaf senescence and defense responses. Plant Cell Physiol. 2017;58:1752-63. https://doi.org/10.1093/ $\mathrm{pcp} / \mathrm{pcx} 112$. 
35. Fernández-Calvo P, Iñigo S, Glauser G, Vanden Bossche R, Tang M, Li B, et al. FRS7 and FRS12 recruit NINJA to regulate expression of glucosinolate biosynthesis genes. New Phytol. 2020;227:1124-37. https://doi. org/10.1111/nph.16586

36. Lei J, Jayaprakasha GK, Singh J, Uckoo R, Borrego EJ, Finlayson S, et al. CIRCADIAN CLOCK-ASSOCIATED1 controls resistance to aphids by altering indole glucosinolate production. Plant Physiol. 2019;181:1344-59. https://doi.org/10.1104/pp.19.00676.

37. Li B, Tang M, Caseys C, Nelson A, Zhou M, Zhou X, et al. Epistatic transcription factor networks differentially modulate Arabidopsis growth and defense. Genetics. 2020;214:529-41. https://doi.org/10.1534/genet ics.119.302996.

38. Brown PD, Tokuhisa JG, Reichelt M, Gershenzon J. Variation of glucosinolate accumulation among different organs and developmental stages of Arabidopsis thaliana. Phytochemistry. 2003;62:471-81. https:// doi.org/10.1016/S0031-9422(02)00549-6.

39. Kastell A, Schreiner M, Knorr D, Ulrichs C, Mewis I. Influence of nutrient supply and elicitors on glucosinolate production in E. sativa hairy root cultures. Plant Cell Tissue Organ Cult. 2018;132:561-72. https://doi.org/ 10.1007/s11240-017-1355-8

40. Klopsch R, Witzel K, Borner A, Schreiner M, Hanschen FS. Metabolic profiling of glucosinolates and their hydrolysis products in a germplasm collection of Brassica rapa turnips. Food Res Int. 2017;100:392-403. https://doi.org/10.1016/j.foodres.2017.04.016.

41. Klopsch R, Witzel K, Artemyeva A, Ruppel S, Hanschen FS. Genotypic variation of glucosinolates and their breakdown products in leaves of Brassica rapa. J Agric Food Chem. 2018;66:5481-90. https://doi.org/10. 1021/acs.jafc.8b01038.

42. Sarikamiş G, Çarik A. Influence of salinity on aliphatic and indole glucosinolates in broccoli (Brassica oleracea var. italica). Appl Ecol. Environ Res. 2017;15:1781-8. https://doi.org/10.15666/aeer/1503_17811788.

43. Yi G, Lim S, Chae WB, Park JE, Park HR, Lee EJ, et al. Root glucosinolate profiles for screening of radish (Raphanus sativus L.) genetic resources. J Agric Food Chem. 2016;64:61-70. https://doi.org/10.1021/acs.jafc. 5 b04575.

44. Blaževic I, Đulovic A, Culic VC, Burcul F, Ljubenkov I, Ruscic M, et al. Bunias erucago L.: glucosinolate profile and in vitro biological potential. Molecules. 2019;24:741-52. https://doi.org/10.3390/molecules24040741.

45. Zuest T, Strickler S, Powell A, Mabry M, An H, Mirzaei M, et al. Independent evolution of ancestral and novel defenses in a genus of toxic plants (Erysimum, Brassicaceae). Elife. 2020;9:e51712. https://doi.org/10.7554/ eLife.51712.

46. Đulović A, Burčul F, Čulić VČ, Ruščić M, Brzović P, Montaut S, et al. Lepidium graminifolium L.: glucosinolate profile and antiproliferative potential of volatile isolates. Molecules. 2021;26(17):5183. https://doi. org/10.3390/molecules26175183.

47. Angelini LG, Tavarini S, Antichi D, Bagatta M, Matteo R, Lazzeri L. Fatty acid and glucosinolate patterns of seed from Isatis indigotica Fortune as bioproducts for green chemistry. Ind Crop Prod. 2015;75:51-8. https:// doi.org/10.1016/j.indcrop.2015.04.010.

48. Mohn T, Hamburger M. Glucosinolate pattern in Isatis tinctoria and I. indigotica seeds. Planta Med. 2008;74:885-8. https://doi.org/10.1055/s2008-1074554.

49. Mohn T, Suter K, Hamburger M. Seasonal changes and effect of harvest on glucosinolates in Isatis leaves. Planta Med. 2008;74:582-7. https:// doi.org/10.1055/s-2008-1074504.

50. Guo Q, Sun Y, Tang Q, Zhang H, Cheng Z. Isolation, identification, biological estimation, and profiling of glucosinolates in Isatis indigotica roots. J Liq Chromatogr Relat Technol. 2020;43:645-56. https://doi.org/ 10.1080/10826076.2020.1780605.

51. Jeon J, Bong SJ, Park JS, Park Y, Arasu MV, Aldhabi NA, et al. De novo transcriptome analysis and glucosinolate profiling in watercress (Nasturtium officinale R. Br.). BMC Genomics. 2017;18:401. https://doi.org/10.1186/ s12864-017-3792-5.

52. Lee KC, Chan W, Liang ZT, Liu N, Zhao ZZ, Lee AWM, et al. Rapid screening method for intact glucosinolates in Chinese medicinal herbs by using liquid chromatography coupled with electrospray ionization ion trap mass spectrometry in negative ion mode. Rapid Commun Mass Spectrom. 2008;22:2825-34. https://doi.org/10.1002/rcm.3669.

53. Kim SJ, Kawaharada C, Jin S, Hashimoto M, Ishii G, Yamauchi H. Structural elucidation of 4-(Cystein-S-yl)butyl glucosinolate from the leaves of Eruca sativa. Biosci Biotechnol Biochem. 2007;71:114-21. https://doi. org/10.1271/bbb.60400.

54. Bu H, Wang LQ, Tang ZQ, Wang B, Bin WZ. Rapid identification of indole alkaloids in Uncaria rhynchophylla by UPLC-ESI-Q-TOF-MS. Chem Eng. 2018;271:20-4. https://doi.org/10.16247/j.cnki.23-1171/tq.20180420.

55. Nguyen T, Marcelo P, Gontier E, Dauwe R. Metabolic markers for the yield of lipophilic indole alkaloids in dried woad leaves (Isatis tinctoria L.). Phytochemistry. 2019;163:89-98. https://doi.org/10.1016/j.phyto chem.2019.04.006.

56. Garciahernandez M, Berardini TZ, Chen G, Crist D, Doyle A, Huala E, et al. TAIR: a resource for integrated Arabidopsis data. Funct Integr Genomics. 2002;2:239-53. https://doi.org/10.1007/s10142-002-0077-z.

57. Cheng F, Liu SY, Wu J, Fang L, Sun SL, Liu B, et al. BRAD, the genetics and genomics database for Brassica plants. BMC Plant Biol. 2011;11:136. https://doi.org/10.1186/1471-2229-11-136.

58. Hofberger JA, Lyons EH, Edger PP, Pires JC, Schranz ME. Whole genome and tandem duplicate retention facilitated glucosinolate pathway diversification in the mustard family. Genome Biol Evol. 2013;5:2155-73. https://doi.org/10.1093/gbe/evt162.

59. Cang W, Sheng YX, Evivie ER, Kong WW, Li J. Lineage-specific evolution of flavin-containing monooxygenases involved in aliphatic glucosinolate side-chain modification. J Syst Evol. 2018;56:92-104. https://doi. org/10.1111/jse.12289.

60. Zhang Z, Xiao J, Wu J, Zhang H, Liu G, Wang X, et al. ParaAT: a parallel tool for constructing multiple protein-coding DNA alignments. Biochem Biophys Res Commun. 2012;419:779-81. https://doi.org/10. 1016/j.bbrc.2012.02.101.

61. Li T, Wang J, Lu M, Zhang TY, Qu XY, Wang ZZ. Selection and validation of appropriate reference genes for qRT-PCR analysis in Isatis indigotica Fort. Front Plant Sci. 2017;8:1139. https://doi.org/10.3389/fpls.2017.01139.

62. Badouin H, Gouzy J, Grassa CJ, Murat F, Staton SE, Cottret L, et al. The sunflower genome provides insights into oil metabolism, flowering and Asterid evolution. Nature. 2017;546:148-52. https://doi.org/10.1038/ nature22380.

63. Wang D, Zhang Y, Zhang Z, Zhu J, Yu J. KaKs_Calculator 2.0: a toolkit incorporating gamma-series methods and sliding window strategies. Genomics Proteomics Bioinformatics. 2010;8:77-80. https://doi.org/10. 1016/S1672-0229(10)60008-3.

64. Koch MA, Haubold B, Mitchell-Olds T. Comparative evolutionary analysis of chalcone synthase and alcohol dehydrogenase loci in Arabidopsis, Arabis, and related genera (Brassicaceae). Mol Biol Evol. 2000;17:148398. https://doi.org/10.1093/oxfordjournals.molbev.a026248.

65. Wang Y, Nie F, Shahid MQ, Baloch FS. Molecular footprints of selection effects and whole genome duplication (WGD) events in three blueberry species: detected by transcriptome dataset. BMC Plant Biol. 2020;20:250. https://doi.org/10.1186/s12870-020-02461-w.

66. Brader G, Mikkelsen MD, Halkier BA, Palva ET. Altering glucosinolate profiles modulates disease resistance in plants. Plant J. 2006;46:758-67. https://doi.org/10.1111/j.1365-313X.2006.02743.X.

67. Bednarek P, Piślewskabednarek M, Svatos A, Schneider B, Doubský J, Mansurova $\mathrm{M}$, et al. A glucosinolate metabolism pathway in living plant cells mediates broad-spectrum antifungal defense. Science. 2009:323:101-6. https://doi.org/10.1126/science.1163732.

68. Clay NK, Adio AM, Denoux C, Jander G, Ausubel FM. Glucosinolate metabolites required for an Arabidopsis innate immune response. Science. 2009;323:95-101. https://doi.org/10.1126/science.1164627.

69. Petersen B, Chen SX, Hansen CH, Olsen CE, Halkier BA. Composition and content of glucosinolates in developing Arabidopsis thaliana. Planta. 2002;214:562-71. https://doi.org/10.1007/s004250100659.

70. Gao JJ, Yu XX, Ma FM, Li J. RNA-Seq analysis of transcriptome and glucosinolate metabolism in seeds and sprouts of broccoli (Brassica oleracea var. italic). PLoS One. 2014;9:e88804. https://doi.org/10.1371/ journal.pone.0088804.

71. Ciska E, Horbowicz M, Rogowska M, Kosson R, Drabinska N, Honke J. Evaluation of seasonal variations in the glucosinolate content in leaves and roots of four European horseradish (Armoracia rusticana) landraces. Polish J Food Nutr Sci. 2017;67:301-8. https://doi.org/10.1515/ pjfns-2016-0029.

72. Noureldin $\mathrm{HH}$, Halkier BA. Piecing together the transport pathway of aliphatic glucosinolates. Phytochem Rev. 2009;8:53-67. https://doi.org/ 10.1007/s11101-008-9110-8. 
73. Wiesner M, Hanschen FS, Schreiner M, Glatt H, Zrenner R. Induced production of 1-methoxy-indol-3-ylmethyl glucosinolate by jasmonic acid and methyl jasmonate in sprouts and leaves of pak choi (Brassica rapa ssp. chinensis). Int J Mol Sci. 2013;14:14996-5016. https://doi.org/ 10.3390/ijms140714996.

74. Moreirarodriguez M, Nair V, Benavides J, Cisneroszevallos L, Jacobovelazquez DA. UVA, UVB light, and methyl jasmonate, alone or combined, redirect the biosynthesis of glucosinolates, phenolics, carotenoids, and chlorophylls in broccoli sprouts. Int J Mol Sci. 2017;18:2330. https://doi. org/10.3390/ijms18112330.

75. Sun MX, Qi XH, Hou LP, Xu XY, Zhu ZJ, Li ML. Gene expression analysis of pak choi in response to vernalization. PLoS One. 2015;10:e0141446. https://doi.org/10.1371/journal.pone.0141446.

76. Rastogi S, Liberles DA. Subfunctionalization of duplicated genes as a transition state to neofunctionalization. BMC Evol Biol. 2005;5:28. https://doi.org/10.1186/1471-2148-5-28.

77. Zhao Q, Yang J, Cui MY, Liu J, Fang YM, Yan MX, et al. The reference genome sequence of Scutellaria baicalensis provides insights into the evolution of wogonin biosynthesis. Mol Plant. 2019;12:935-50. https:// doi.org/10.1016/j.molp.2019.04.002.

78. Kang S-H, Pandey RP, Lee C-M, Sim J-S, Jeong J-T, Choi B-S, et al. Genome-enabled discovery of anthraquinone biosynthesis in Senna tora. Nat Commun. 2020;11:5875. https://doi.org/10.1038/ s41467-020-19681-1.

79. Wang J, Xu S, Mei Y, Cai S, Gu Y, Sun M, et al. A high-quality genome assembly of Morinda officinalis, a famous native southern herb in the Lingnan region of southern China. Hortic Res. 2021;8:135. https://doi. org/10.1038/s41438-021-00551-w.

80. Miryeganeh M, Marlétaz F, Gavriouchkina D, Saze H. De novo genome assembly and in natura epigenomics reveal salinity-induced DNA methylation in the mangrove tree Bruguiera gymnorhiza. New Phytol 2021;n/a n/a. doi:https://doi.org/10.1111/nph.17738.

81. Patterson EL, Saski CA, Sloan DB, Tranel PJ, Westra P, Gaines TA. The draft genome of Kochia scoparia and the mechanism of glyphosate resistance via transposon-mediated EPSPS tandem gene duplication. Genome Biol Evol. 2019;11:2927-40. https://doi.org/10.1093/gbe/ evz198.

82. Aagaard JE, Willis JH, Phillips PC. Relaxed selection among duplicate floral regulatory genes in Lamiales. J Mol Evol. 2006;63:493. https://doi. org/10.1007/s00239-005-0306-X.

83. Cheng F, Wu J, Cai X, Liang J, Freeling M, Wang X. Gene retention, fractionation and subgenome differences in polyploid plants. Nat Plants. 2018;4:258-68. https://doi.org/10.1038/s41477-018-0136-7.

84. Huang H, Yao H, Wang LL, Si LJ, Yang QL, Gu ZY. Anti-flu effect of compound Yizhihao granule and its effective components. Chinese Herb Med. 2017;9:80-5. https://doi.org/10.1016/S1674-6384(17)60080-7.

85. Nie LX, Dai Z, Ma SC. Stereospecific assay of (R)- and (S)-goitrin in commercial formulation of Radix isatidis by reversed phase highperformance liquid chromatography. J Autom Methods Manag Chem. 2017;2017:2810565. https://doi.org/10.1155/2017/2810565.

86. Bones AM, Rossiter JT. The myrosinase-glucosinolate system, its organisation and biochemistry. Physiol Plant. 1996;97:194-208. https://doi. org/10.1111/j.1399-3054.1996.tb00497.x.

87. Dohenyadams T, Redeker KR, Kittipol V, Bancroft I, Hartley SE. Development of an efficient glucosinolate extraction method. Plant Methods. 2017;13:17. https://doi.org/10.1186/s13007-017-0164-8.

88. ISO 9167-1 1992. Rapeseed - determination of glucosinolate content Part 1: method using high performance liquid chromatography. 2013.

89. Grosser K, Van Dam NM. A straightforward method for glucosinolate extraction and analysis with high-pressure liquid chromatography (HPLC). J Vis Exp. 2017;212:e55425. https://doi.org/10.3791/55425.

90. Clarke DB. Glucosinolates, structures and analysis in food. Anal Methods. 2010;2:310-25. https://doi.org/10.1039/B9AY00280D.

91. La GX, Shi LN, Fang P, Li YJ. Identification of desulpho-glucosinolates in Chinese kale by HPLC-PDA-ESI/MS. Food Sci. 2009;30:411-5.

92. Burke DG, Cominos X. Identification of desulfoglucosinolates using positive-ion fast atom bombardment mass spectrometry. J Agric Food Chem. 1988;36:1184-7. https://doi.org/10.1021/jf00084a015.

93. Koren S, Walenz BP, Berlin K, Miller JR, Bergman NH, Phillippy AM. Canu: scalable and accurate long-read assembly via adaptive $k$-mer weighting and repeat separation. Genome Res. 2017;27:722-36. https://doi.org/ 10.1101/gr.215087.116.

94. Ruanjue.WTDGB. 2018. https://github.com/ruanjue/wtdbg. Accessed 5 May 2018.

95. Chin C-S, Peluso P, Sedlazeck FJ, Nattestad M, Concepcion GT, Clum A, et al. Phased diploid genome assembly with single-molecule real-time sequencing. Nat Methods. 2016;13:1050-4. https://doi.org/10.1038/ nmeth.4035.

96. Chakraborty M, Baldwin-Brown JG, Long AD, Emerson JJ. Contiguous and accurate de novo assembly of metazoan genomes with modest long read coverage. Nucleic Acids Res. 2016;44:e147. https://doi.org/10. 1093/nar/gkw654.

97. Altschul SF, Gish W, Miller W, Myers EW, Lipman DJ. Basic local alignment search tool. J Mol Biol. 1990;215:403-10. https://doi.org/10.1016/ S0022-2836(05)80360-2.

98. Finn RD, Bateman A, Clements J, Coggill P, Eberhardt RY, Eddy SR, et al. Pfam: the protein families database. Nucleic Acids Res. 2014;42:222-30. https://doi.org/10.1093/nar/gkt1223.

99. Marchlerbauer A, Lu SN, Anderson JB, Chitsaz F, Derbyshire MK, Deweesescott C, et al. CDD: a conserved domain database for the functional annotation of proteins. Nucleic Acids Res. 2011;39:225-9. https:// doi.org/10.1093/nar/gkq1189.

100. Wilkins MR, Gasteiger E, Bairoch AM, Sanchez JE, Williams KL, Appel $\mathrm{RD}$, et al. Protein identification and analysis tools in the ExPASy server. Methods Mol Biol. 1999;112:531-52. https://doi.org/10.1385/1-59259584-7:531.

101. Chou KC, Bin SH. A new method for predicting the subcellular localization of eukaryotic proteins with both single and multiple sites: Euk-mPLoc 2.0. PLoS One. 2010;5:e9931. https://doi.org/10.1371/journ al.pone.0009931.

102. Voorrips RE. MapChart: software for the graphical presentation of linkage maps and QTLs. J Hered. 2002;93:77-8. https://doi.org/10.1093/ jhered/93.1.77.

103. Wang Y, Tang H, DeBarry JD, Tan X, Li J, Wang X, et al. MCScanX: a toolkit for detection and evolutionary analysis of gene synteny and collinearity. Nucleic Acids Res. 2012;40:e49. https://doi.org/10.1093/nar/gkr1293.

104. Villanueva RAM, Chen ZJ. ggplot2: elegant graphics for data analysis (2nd ed). Meas Interdiscip Res Perspect. 2019;17:160-7. https://doi.org/ 10.1080/15366367.2019.1565254.

105. NCBI Resource Coordinators. Database resources of the National Center for biotechnology information. Nucleic Acids Res. 2017;45:D12-7. https://doi.org/10.1093/nar/gkw1071.

106. Hubbard T, Barker D, Birney E, Cameron G, Chen Y, Clark L, et al. The Ensembl genome database project. Nucleic Acids Res. 2002;30:38-41. https://doi.org/10.1093/nar/30.1.38.

107. Nordberg H, Cantor M, Dusheyko S, Hua S, Poliakov A, Shabalov I, et al. The genome portal of the Department of Energy Joint Genome Institute: 2014 updates. Nucleic Acids Res. 2014;42:D26-31. https://doi.org/ 10.1093/nar/gkt1069.

108. Edgar RC. MUSCLE: multiple sequence alignment with high accuracy and high throughput. Nucleic Acids Res. 2004;32:1792-7. https://doi. org/10.1093/nar/gkh340.

109. Price MN, Dehal PS, Arkin AP. FastTree 2--approximately maximumlikelihood trees for large alignments. PLoS One. 2010;5:e9490. https:// doi.org/10.1371/journal.pone.0009490.

110. Kumar S, Stecher G, Tamura K. MEGA7: molecular evolutionary genetics analysis version 7.0 for bigger datasets. Mol Biol Evol. 2016;33:1870-4. https://doi.org/10.1093/molbev/msw054.

\section{Publisher's Note}

Springer Nature remains neutral with regard to jurisdictional claims in published maps and institutional affiliations. 